\title{
Mapping Punishment: Provincial Places to Dissect
}

\section{INTRODUCTION}

In 1723, Messenger Monsey started practicing as a physician in Bury St. Edmunds. He advertised his services in both physic and surgery to try to attract new clients to a town considered to be a medical backwater in East Anglia. Even so, for a man born in Norfolk, setting up business in an area he thought he knew well proved to be a major career challenge. Neither his degree in classics from Pembroke College in Cambridge, nor his apprenticeship to a physician at Norwich, prepared him for the financial cut and thrust of provincial doctoring. He soon found out why small provincial towns like Bury did not attract ambitious medical men in the eighteenth-century. Monsey thought, incorrectly, that in medical business he would be advantaged by a lack of qualified doctors in Suffolk. He presumed that patients would pay his fees promptly to secure reliable medical services. It was worrying when he calculated that his gross medical profit was about ' $£ 300$ per year' and it was not sufficient to keep him solvent. ${ }^{1}$ He worked unceasingly because it was a constant financial strain to pay the rent on his business premises, the livery fees for several fast horses and a sturdy carriage, and manage the slow cash-flow of indebted clients. Monsey was then very relieved when he won the local patronage of $2 \mathrm{nd}$ Earl Godolphin, son of Queen Anne's Lord Treasurer and grandson of the first Duke of Marlborough. The young peer had suffered an 'apoplectic compliant' [a minor stroke] one night returning to his family seat at

(C) The Author(s) 2016

E.T. Hurren, Dissecting the Criminal Corpse, Palgrave

Historical Studies in the Criminal Corpse and its Afterlife,

DOI 10.1057/978-1-137-58249-2_5 
Newmarket. His manservant redirected the carriage to the nearest town, at Bury, and called on Monsey who saved Godolphin's life. In return, he offered to sponsor Monsey's application as a physician to Chelsea Hospital in London. Monsey's obituary-writer recounted that few could have predicted this successful outcome for someone so unseasoned in medical fashions:

He began business at Bury [St Edmunds], where he experienced the common fate of country practice - constant fatigue, long journeys and short fees; and in rusty wig, dirty boots, and leather breeches, might have degenerated into a hum-drum provincial doctor, his merits not diffused beyond a county chronicle and his medical errors concealed in the country churchyard. ${ }^{2}$

Other diarists wrote about the difficulties of making inroads into a local medical market-place regardless of how well-connected qualified surgeons had become since the Murder Act. Richard Hodgkinson (encountered in Chapter 4 on a visit from the country to Surgeon's Hall) corresponded on 6 March 1828 about the history of business strife in the North of England:

Mr Bedford (whom I think you may remember) was considered an eminent Surgeon, but tho' he married in Bolton, and had good connections, he was obliged to leave the Town some Years ago and settle in Liverpool. A Mr Moore who has long resided in Bolton has the leasing Practice as a general Surgeon and Apothecary and has the best Families but there are those who vie with him and some of inferior Rank. A Dr Black some years ago settled in Bolton as a Physician, he married but died young and was succeeded by another Dr Black (no Relation I believe) who, on his coming, was so violently attacked by the whole body of the medical men in Bolton that he was obliged to turn on his Assailants and fairly write them down in Public prints. The common Surgery business is all engrossed by a man named Taylor, a Relative of the Oldfield Lane Doctor whose Practice he imitates. ${ }^{3}$

Getting established as a surgeon required tact, patience, fortitude, determination, patronage, good local connections, and sharp elbows. If these did not work then the surgeon could be run out of town. Unless, that is, he was prepared to take some sort of evasive action by harnessing the power of the press, publishing original research in respected medical journals, or taking on post-mortem work. Above all, it was essential to watch one's back because competition was fierce and medical rivalries all too common. This meant that few could afford to ignore the chance that criminal 
dissections afforded. Measuring business success was though dependent on three elusive factors: first, maintaining a sense of local belonging especially if an outsider coming into the community; second, developing a reputation for medical innovation; and thirdly, displaying a steely determination to succeed in the neighbourhood. It was increasingly necessary not just to be able to identify each patient's troubling symptoms, but to verify their diagnosis too. Medical consumers needed convincing that doctoring was not just the art of storytelling but incorporated genuine medical improvement. This required surgeons to produce new opinions based on a working knowledge of dissection. Hence, this chapter is all about where exactly post-mortems could potentially be improved by criminal dissection work in England. It examines execution places, their actual supply networks, and the distribution of corpses on a regional basis. This empirical picture is also concerned with the spatial architecture of dissection spaces and their alignment in communities, as well as their economies of scale. In the historical literature the number of bodies, their delivery and dispersal, developed at a provincial pace that remains very poorly understood. In a theatre of punishment, the capital looked centre-stage but it lost its starring role by the early nineteenth-century. Historians of culture, crime and medicine need therefore to rediscover medico-legal realities outside the metropolis, and to do so over the long duration. It is insufficient to rely either on a basic reading of the legal rhetoric of the capital legislation when it was first passed or to maintain a blind faith in accepted theories about the condemned body in a history of ideas without testing them in the archives. Instead there needs to be a spatial mapping of actual punishment provision beyond London. Research reveals that dissecting was not a theatre of make-believe but a compelling material showcase in even the remotest parts of England.

Dissection cases known to have been generated by the Murder Act have therefore been mapped in Section 1 of this fifth chapter. Data is presented for the first time on actual supply mechanisms. A quantitative analysis of Sheriff's Cravings found in the National Archives and court records retained by country record offices together form the bedrock of this chapter's empirical findings. Financial expenses claimed back by executioners from central government have been used to reconstruct just how many murder cases had a secure conviction and dissection verdict actioned on a county-by-county basis. These figures provide accurate information about the chain of supply and its regional profile from 1752 to 1832. A significant discovery is the provincial spectrum of large, medium and smallscale punishment venues for post-execution rites. In the North of England and Midlands many penal surgeons used small medical dispensaries; 
others worked in the lobby of Shire Halls. These were very public places to dissect in the community before voluntary hospitals were built. In the Southern counties and West Country, the condemned were dissected either in the dead-houses of newly constructed infirmaries or on the business premises of penal surgeons who sometimes made use of a prison room for post-mortem work too. What all the venues had in common was their symbolic architectural alignment near local courtrooms. There, crowds of people gathered to satisfy their 'public curiosity' and stayed behind to get involved in the post-execution encore.

Travelling to these punishment sites involves selecting places that represent their region and then studying them in-depth in Section 2. A sightseeing tour of dissection rooms thus begins in major 'hanging-towns' like Lancaster in the North West. These are compared to equivalent punishment sites in growing industrial areas across the Pennines in cities such as Leeds and other major towns in Yorkshire. Moving then down to Derby, a semiindustrial location rich in archive sources, illuminates how leading surgeons set medico-legal standards across the Midlands. It is feasible to explore who got criminal corpses, what they did with them, and where exactly punishments happened. The evidence highlights some of the logistics of operating a local economy of supply and those findings are then compared to smaller towns in East Anglia akin to Bury St Edmunds where Monsey Messenger worked. The aim being to find out a lot more about what dissection days were really like, who organised them, and which penal surgeons staffed the sessions. To achieve this, it is also necessary to travel into Devon, Dorset and down to Cornwall. Our sight-seeing in this way takes a circular route using Map 5.1 (see, Section 1), starting at the top of England and ending at its equivalent West Country nexus. Exploring these forgotten punishment spaces is all about revisiting their symbolic meaning on location and walking figuratively with the condemned ready-made for criminal dissection.

\section{Facts and Figures: Successful Convictions and Criminal Dissections}

In eighteenth-century homicide cases presiding judges delegated the capital sentence to a local Sheriff. He had the legal right to reclaim from central government medico-legal expenses incurred in order to carry out the death sentence and punish the condemned post-execution. This included the cost of transportation, scaffold-building, rope manufacture, paying 
the hangman, and any surgical fees. These financial returns are known as Sheriffs Cravings and they were reimbursed annually by the Exchequer of the Treasury in London. For this book, they have been cross-matched to available Assizes records held in county record offices. Together extensive record linkage work has produced quantitative data that shows in Figure 5.1 how a total of 1,150 murderers were successfully convicted and sentenced to dissection under the Murder Act in England between 1752 and 1832. ${ }^{4}$ These were the official number of bodies that were made available to designated penal surgeons. Since only eight per cent ( 93 people) were pardoned before execution and thirteen per cent ( 147 bodies) were hung in chains on the gibbet, rather than dissected, the vast majority of seventy nine per cent (908 criminals) corpses entered the medical economy of supply. ${ }^{5}$

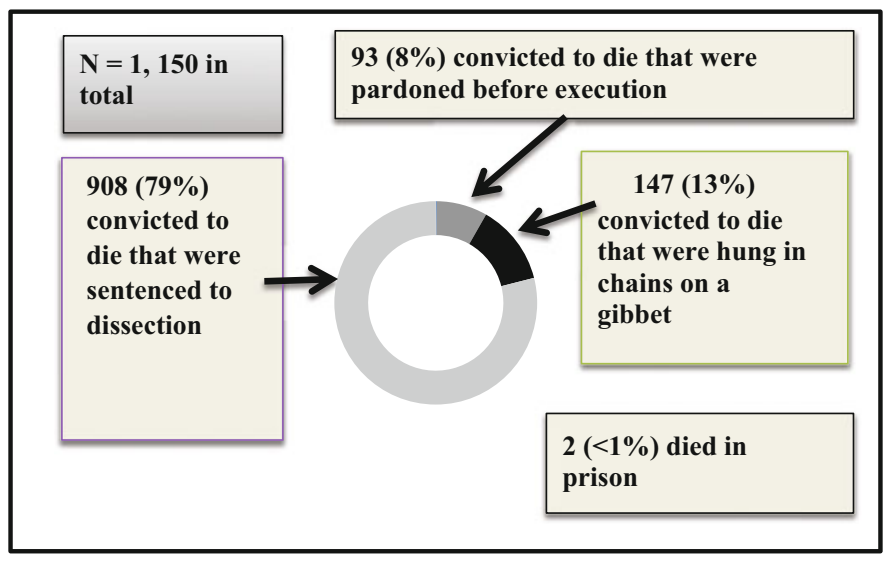

Figure 5.1 Condemned bodies sentenced to death with post-mortem punishment under the Murder Act, circa 1752 to 1832.

Figure 5.2 then plots the actual rates of supply per annum, with conviction rates (the solid black line) displayed against a 5 -year moving average (the dotted line). The data shows four distinctive periods of dissection supply. From 1752 an average of 17 bodies was supplied each year until 1800. In a second phase around 1801 there were just 4 in an annual cycle, but this recovered to 15 by 1809 . Supply figures during a third phase were 
more erratic. They reached 18 a year by 1812 , rose to 25 by 1813 , but fell back to 15 in 1815 , before doubling to a sharp peak of 30 by 1816. In a fourth phase, from 1817 supply fell to 10 bodies per year until just before the Anatomy Act was passed in 1832. The symbolic importance of these supply levels for law and order should not be under-estimated and needs therefore to be carefully set in its historical context. Yet, it is self-evident that the official body business was inadequate for the needs of an expanding medical fraternity. It was debatable that future professional recognition could be so dependent on the expansion of human anatomy teaching when there was such a significant shortfall in supply from the gallows. The medical irony was that not enough criminals were committing homicide. To appreciate the differences between a London education and one in the provinces it is essential to utilise the data-set to compare and contrast supply levels in the capital with a regional picture for the time period too.

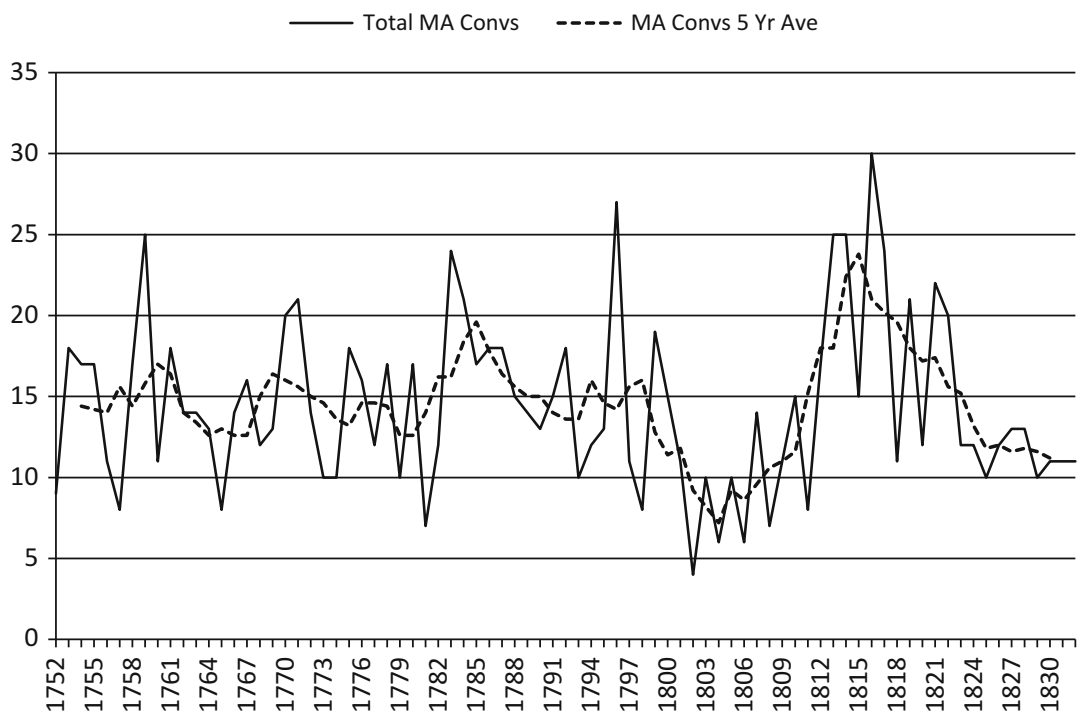

Figure 5.2 Convictions under the Murder Act, 1752 to 1832 (including Admiralty cases). 
Simon Chaplin has estimated that ' 80 ' bodies were acquired by Surgeon's Hall between 1752 and $1832 .{ }^{6}$ If correct, this means that of the 908 available in the entire chain of supply only 8.81 per cent came into the main dissection venue that has been so dominant in the historical literature for London. Using more accurate figures compiled for this study from the Sheriff's Cravings and cross-matching these to Old Bailey records means we can begin to engage with change over time, regional variation, and reassess the supply trends in the capital in a more sophisticated way. Inside London, 170 bodies were recorded as sentenced to dissection for murder and, of these, 148 entered the chain of supply (ten were pardoned \& twelve committed suicide on the eve of execution). This equates to some 16.29 per cent (almost double Chaplin's original estimate) of the overall total of 908 bodies. Figure 5.3 then shows that London body-supply networks had primacy, but this dominance only happened until 1800 .

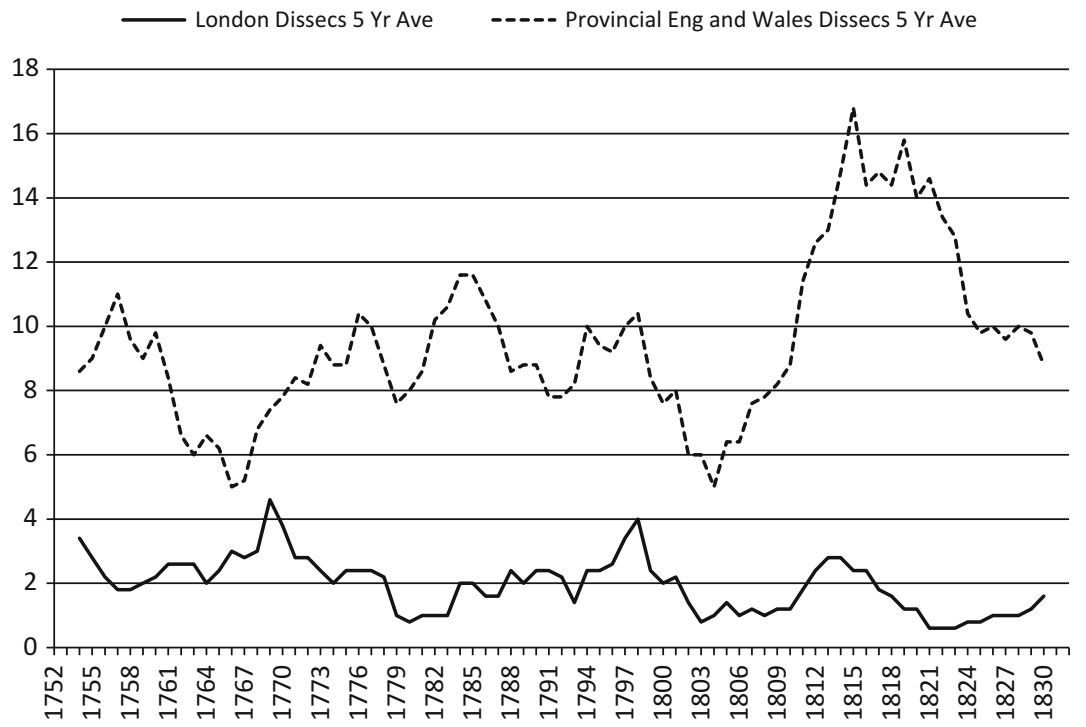

Figure 5.3 Corpses made available to surgeons under the Murder Act, in London compared to provincial England, circa 1752 to 1832. 
At a time when Surgeon's Hall started to be seen as lacklustre, its supply lines were on a downward trend. This sets in context why the Hunter brothers for instance by acquiring fresh corpses exhumed from churchyards relied on an illegal supply-mechanism to dominate private medical education in London. It is then a noteworthy finding that after 1804 a penal surgeon had a much better chance of dissecting on a regular basis from legal sources that became available in the provinces, rather than the capital. If he wanted to attract fee-paying pupils to boast his income streams it was prudent to be networked into medico-legal circles in a county setting.

It follows that between 1812 and 1824 when the death of the brain at criminal dissections was regarded as a medical frontier, an ambitious penal surgeon relied on the local Assizes outside of the capital to supply his body needs for original research and teaching. There were of course areas of the country that were better to be located in than others to take advantage of official supply mechanisms. Before we map these and their punishment places on a regional basis (see, Map 5.1, Section 1 below), it is important to appreciate that what mattered to medical men was whether or not when a criminal was sentenced to dissection that body actually entered a chain of supply in each county. The death sentence could after all be changed to hanging in chains, or the judge might be merciful and hand back the body to the relatives. They also had the discretion to pardon or lessen the sentence before leaving town. Of those that were made available in an area, some bodies might be moved to another location out of the county in which they were generated. This often happened in 'hanging-towns' like Lancaster and across Yorkshire where convicted criminals were executed together and so there was sometimes a supply surplus. It made sense to send a selection of corpses to another area before they decayed too fast to be dissected. Later the theme of body-redistribution across county boundaries is elaborated in Section 2 . In the meantime, some basic observations about bodies actually made available in English counties can be made from Figures 5.4, 5.5 and 5.6 that appear sequentially below, on the next few pages.

Figure 5.4 shows that there were ten key locations in England where the condemned were obtained for dissection on a regular basis, excluding London. ${ }^{7}$ In the North of England, the main body-supply places were Lancashire (a total of 35 corpses) from an area extending down into Greater Manchester, accompanied by the main 'hanging-towns' across Yorkshire (with 53 bodies overall) like Leeds, making up a total chain of 88 supplybodies. In the Midlands, it was Warwick that was the most active supplier totalling 33 criminal corpses. Across the West Country, the counties of Devonshire (53), Gloucestershire (31), Somerset (33), and Wiltshire (33) 


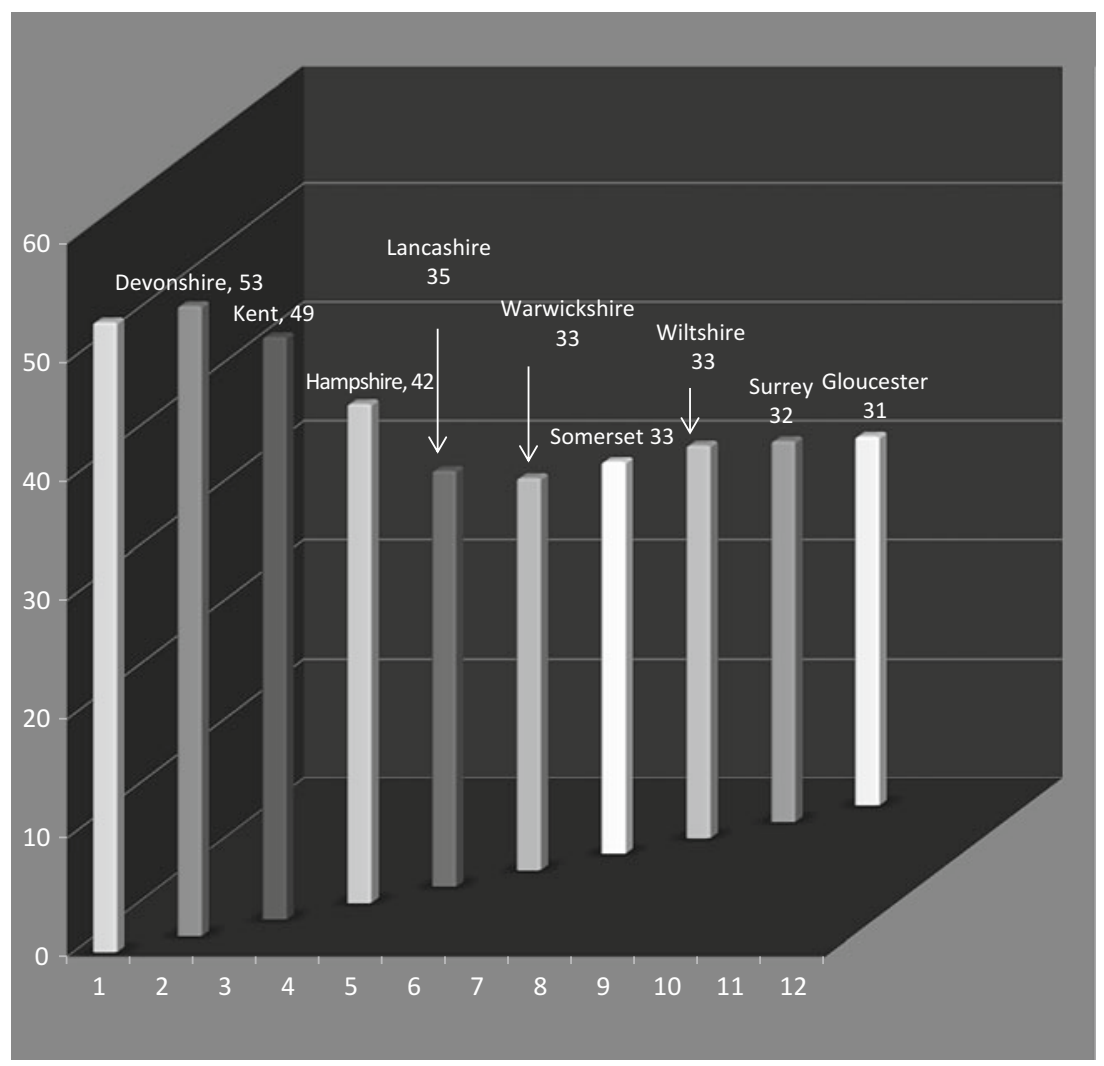

Figure 5.4 The first-rank of ten leading English counties that sentenced the condemned to dissection and punished them post-mortem circa 1752 to 1832.

together delivered 130 bodies for dissection. That meant that in the South of England, Kent (49) and Hampshire (42) were the two leading counties supplying together 123 condemned bodies. It is notable that all of these key suppliers shared a skilled hangman with those in the second rank of county suppliers (cross refer, Figure 5.5). He kept up an efficient supply in his two main hanging towns of Lancaster and Warwick, and did lots of related work for Leicester and Gloucester too. Unsurprisingly penal surgeons made sure they got to know him personally. On location they were thus by 1800 remarkably well placed to exploit county towns linked 
in the supply chain by their chosen hangman. Their London counterparts lacked an equivalent geographic coverage. In summary then 394 bodies were supplied to penal surgeons from the top ten shires that hanged and dissected on a regular basis under the Murder Act in England.

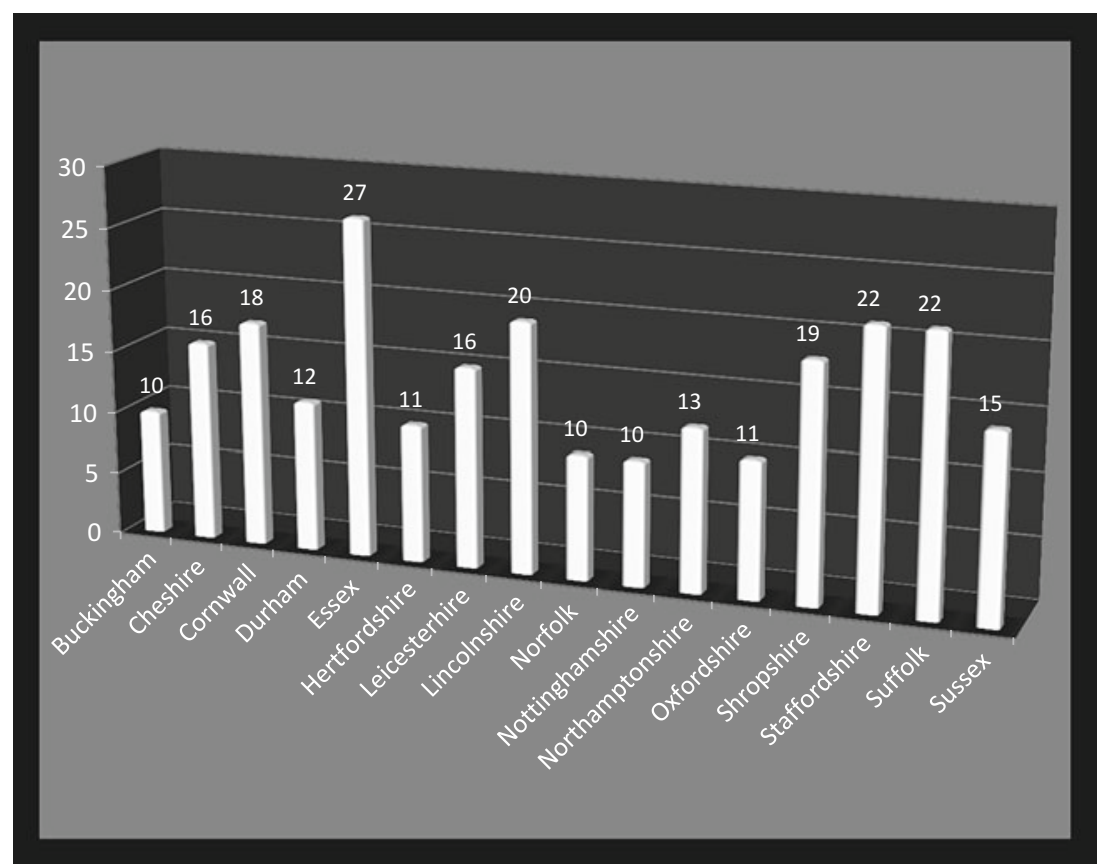

Figure 5.5 The second-rank of body-suppliers in English counties where criminal corpses were made available for dissection, circa 1752 to 1832 .

Figure 5.5 reveals those places that fell into a second-rank chain of supply amongst English counties. None of these places identified ever supplied more than thirty bodies in total over the timeframe but the symbolic importance of their delivery schemes should not be under-estimated. In the North West the palantine of Durham with 12 bodies and its equivalent at Cheshire with 16 bodies predominated. In an area covering the Midlands heartland and East Anglia there were 113 corpses in the chain of supply. Stretching down into the South Eastern counties 38 of the condemned were dissected. 
In the Southern belt around Oxfordshire there were 21 cadavers, and as far down as Sussex 15 gallows bodies were utilised by local surgeons. This left Cornwall with 18 corpses, the most distant outpost from London. Later we will encounter the different types of anatomical venues in these vicinities and what made the nature of the dissection work undertaken there so distinctive. Meantime the collected data shows that all of these mid-range suppliers delivered 252 bodies in total for criminal dissection.

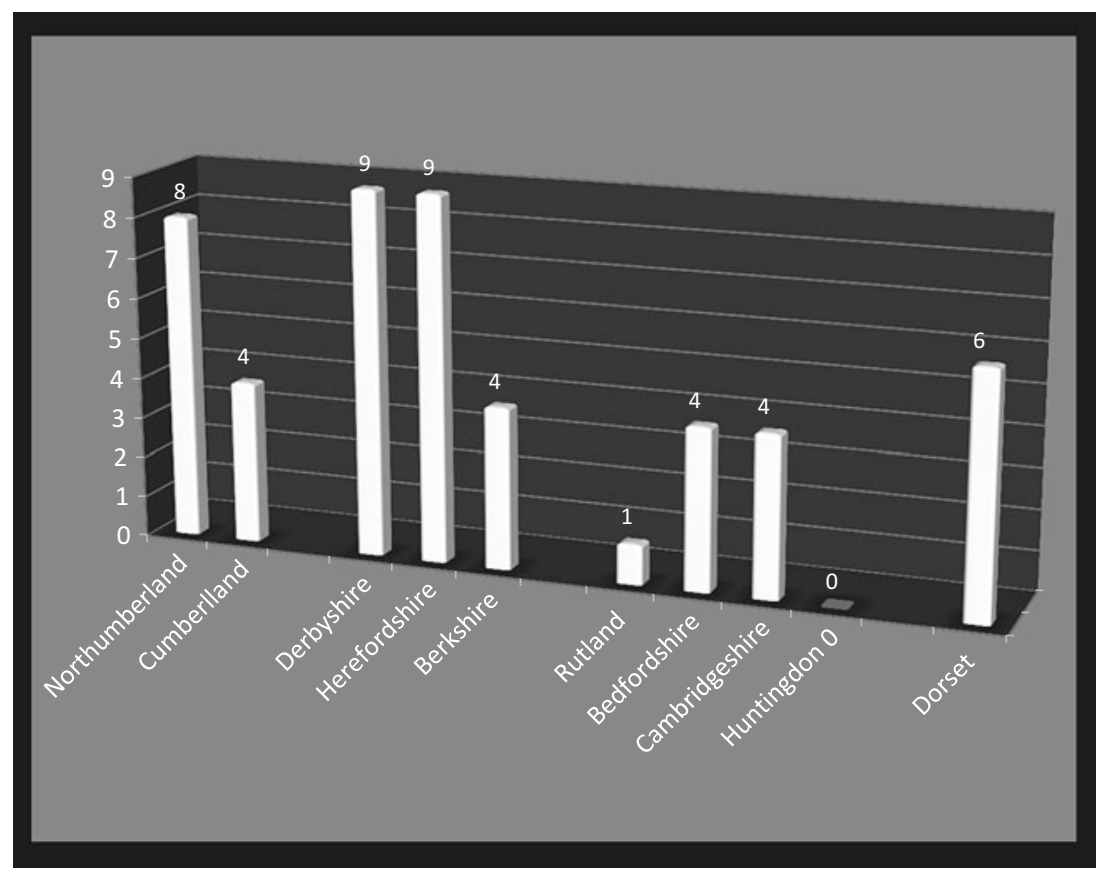

Figure 5.6 The third-rank of body-suppliers in English counties where criminal corpses were made available for dissection, circa 1752 to 1832.

Figure 5.6 concludes this geographical picture of English counties by identifying the third-rank of body-supply locations. These were places that never supplied more than 10 criminal cases in total: although again their smaller numbers must not be understated symbolically. The public reception of a criminal dissection was usually more enhanced where it 
was a rarity. It really depended on the circumstances of the murder conviction, the scientific credentials of the penal surgeons doing the postmortem punishment, and where exactly the corpse was dissected. Derby for instance supplied a total of 10 bodies in this time period. That supply figure looks insignificant but each criminal dissection, as we shall see later in Section 2, created widespread publicity. It also involved some sort of original research into the death of the criminal brain. Such findings stress why it is important to avoid broad generalisations about the insignificance of provincial rites. Often cultural studies neglect to appreciate that some locations were sometimes chosen for strategic reasons, so much so that bodies from Nottingham (in the second-rank) were often shared with places such as Derby (in the third-rank) because the dissection work done in the latter was considered prestigious. It thus sometimes could enhance the deterrence value of punishment in violent criminal cases.

To bring all of these locations together into a national picture of postmortem 'harm' it is then necessary to analyse their body-supply network by mapping them together. This book has found that these can be categorized broadly in one of four punishment zones that relate to typical post-execution venues on location illustrated in Map 5.1 (see overleaf).

In the North of England to the left-hand side of the Pennines it was common to dissect criminal corpses in small public dispensaries, especially in growing industrializing towns like Preston. Cities like Manchester and Liverpool were the exception to this rule because they already had constructed a voluntary hospital in 1752 and 1749 respectively, with a morgue in which to do criminal dissections around the time of the Murder Act (see, Band A, Map 5.1). The same pattern can be seen to the North East too. Small medical dispensaries were utilised as dissection venues in places like Halifax and Wakefield. Meanwhile Newcastle developed its Surgeon's Hall (as we saw in Chapter 4) at a time when York boasted from 1740 that it had a fully-equipped dead-house at its voluntary hospital to house postmortem rites. Eventually however it was Leeds from 1767 that established itself as the place to dissect in Yorkshire. It competed nevertheless with small medical dispensaries for supply for longer than many historians of the period have appreciated.

Moving then down the country into a Midlands heartland it was the local Shire Hall that became the main criminal dissection venue. It was usually located conveniently in the centre of a semi-industrial town like Derby, where the Assizes was held, and so could be used for criminal dissections. This arrangement continued until bodies were moved to local 


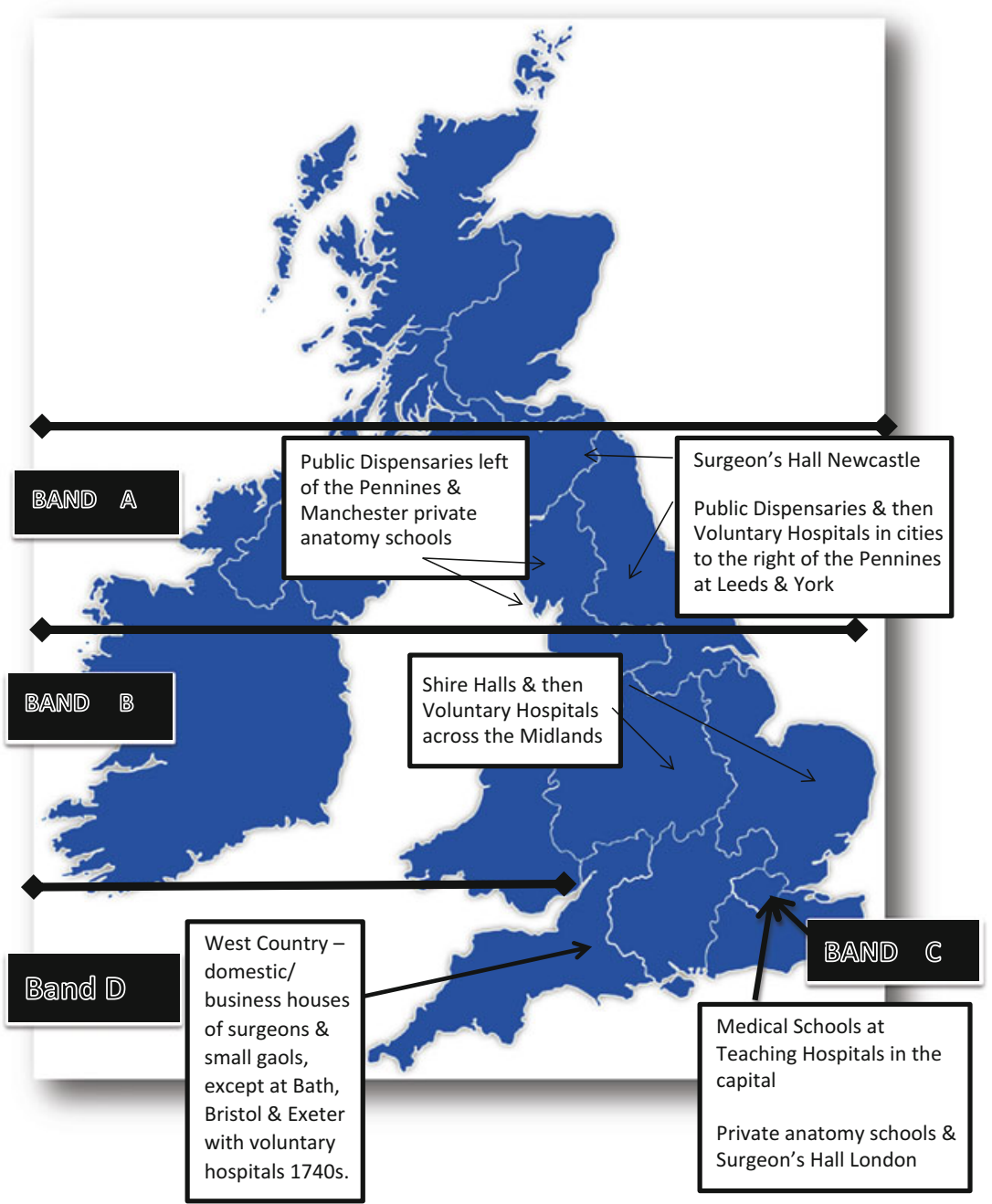

Map 5.1 Geography of punishment zones (Bands A, B, C and D) and their corresponding dissection venues in England, c. 1752 to 1832. 
voluntary hospitals once they were constructed after the Murder Act (see Table 5.1, below). It took time for local elites to raise money to establish a hospital venue from charitable funding. When they eventually did each provided a dedicated anatomical space for local surgeons and facilities were often shared with coroners to save money. The Shire Hall was thus a pivotal medical space in provincial life (see, Band B, Map 5.1) until gradually at Leicester (1771) and Nottingham (1782), for instance, the laying of a cornerstone of a new voluntary hospital marked a change of venue for the post-mortem journey of the criminal corpse.

Travelling south on the Great North Road to the capital meant encountering a different scale of medical market-place the closer one got to London (see, Band C, Map 5.1). The capital was different from everywhere else, except Newcastle and Edinburgh, because all three had a purpose-built Surgeon's Hall. Inside London, large teaching hospitals began to develop and alongside them anatomical schools relocated. Medical education thus gradually became formalized. In the counties that surrounded the capital like Kent, Surrey, Middlesex and Essex, often bodies were moved into a central London location. Occasionally in the case of very violent murders the condemned was sometimes dissected on location because of the symbolic impact of staging a criminal dissection for its deterrence value in the actual place that a murder took place. Yet, this was not the general rule because of the reorganisation of institutional structures of medical education nearby and the availability of dead-houses.

Travelling then by express coach out of London towards the West Country, across the River Severn to Bristol or down to Cornwall, something different was happening compared to everywhere else (see, $\underline{\text { Band D }}$, Map 5.1). These where places that Peter King has recently described as remoter areas where the capital code for property offences was resented and therefore seldom enacted in the Western outreaches. ${ }^{8}$ Instead local people preferred to police themselves in cases of sheep stealing, housebreaking and highway robbery. Fewer 'extras' were available because criminal justice was so localized. Homicide however remained a different order of criminal offence. It was punished severely but in anatomical spaces that tended to be more domestic and small-scale before the 1790s. The premises where individual surgeons lived and worked were often used to conduct punishments, and this made sense because local autopsies on behalf of coroners were done in these sorts of places too. Individual surgeons tended to bid for criminal corpses at the local Assizes by making a personal application to the courthouse. They might also co-opt a room at the prison for reasons of convenience. Once however 
Table 5.1 Establishment of English provincial voluntary hospitals where postmortem punishment is known to have taken place after opening, circa 1730 to 1810

\begin{tabular}{llll}
\hline Date opened & Location & Date opened & Location \\
\hline $\mathbf{1 7 3 5}$ & Bristol & $1752-$ Murder Act & Manchester \\
$\mathbf{1 7 3 6}$ & Winchester & 1755 & Gloucester \\
$\mathbf{1 7 4 0}$ & York & 1755 & Chester \\
$\mathbf{1 7 4 2}$ & Bath & 1766 & Cambridge \\
$\mathbf{1 7 4 3}$ & Devon and Exeter & 1767 & Leeds \\
$\mathbf{1 7 4 4}$ & Northampton & 1767 & Salisbury \\
$\mathbf{1 7 4 5}$ & Worcester & 1769 & Stafford \\
$\mathbf{1 7 4 7}$ & Shrewsbury & 1770 & Oxford \\
$\mathbf{1 7 4 9}$ & Liverpool & 1771 & Leicester \\
$\mathbf{1 7 5 1}$ & Newcastle & 1772 & Norfolk and Norwich \\
& & 1782 & Nottingham \\
& & 1797 & Sheffield \\
& & 1810 & Derby \\
\hline
\end{tabular}

Source: Ernest Reginald (1988), The Life and Times of the Royal Infirmary at Leicester: The Making of a Teaching Hospital 1766-1800 (Leicester: Leicester Medical Society), p. 535

local voluntary hospitals were established this is where bodies were then sent by the 1820s too. In Bath, Bristol, and Exeter, a voluntary hospital had been established in the 1740s and having coincided with the Murder Act there was a public morgue to dissect in. But in outlying areas of Dorset and Launceston in Cornwall, bodies were given to individual surgeons to dissect at home or sent back to a local gaol surgeon to depose of as he saw fit. Over our entire chronological focus the majority of criminal dissections happened up to the 1790s in either a Shire Hall, medical dispensary, the domestic premises of a surgeon, or a local gaol. After 1800, law and justice was more formulaic taking place inside a dedicated dead-house or morgue of a voluntary hospital.

This data taken in its entirety reveals why it was that local people increasingly saw criminal dissections as a medical event they could and should attend because they were happening in their community by the early nineteenth-century. We therefore need to visit actual dissections days staged in rural and urban England. The aim in the next section is to embark on a medical sight-seeing tour of Map 5.1. In so doing, we will be looking in-depth at archetypal places of punishment, those congregated at the scene, and how exactly they were staffed by medical men and others associated with capital rites. The representative examples have each been recently rediscovered in provincial archives. 


\section{Dissection Days: 'HaLF Suffocated and SqueEzed TO A JELLY}

In all the data illustrated on Map 5.1, we saw that Band A to the left of the Pennines had a main dissection venue at Lancaster. In the eighteenthcentury it was known as 'The Hanging Town' in the North of England. This was because no other Assizes outside of London hanged more criminals in the long eighteenth-century. It has been estimated that between 1782 and 1812 some 71 convicts were hanged for capital offences, and of these 71 some 35 (fifty per cent) became available for dissection. Lancaster was situated in the Duchy Palantine of Lancaster which since 1351 had special judicial powers adjudicated to try all capital offences for the North West, as far down as Manchester and up to Liverpool. By legal custom Lancaster was the only Assize court in the vicinity of a large sweep of manufacturing towns and rural villages until 1835. ${ }^{9}$ Eighteenth-century paintings suggest that prisoners were normally tried together for various capital offences accompanied by huge crowds that congregated outside Lancaster Castle. Architectural drawings of the Castle of 1822 likewise establish this medico-legal scenery. ${ }^{10}$

Before 1800 all those convicted of homicide were hanged on Gallow's Hill on the Lancaster moors, close to an area known today as Williamson Park. By tradition the condemned walked in street-procession taking a last drink at the Golden Lion public house in the town. Coffins were carried in a cart and beside it the condemned walked to their fate accompanied by the crowd. Local accounts stress that people came from across the North West to witness 'The Hanging Day'. After 1800 however executions were moved to the outside of the precincts of Lancaster Castle, near the churchyard. The hangman now erected a gallows at Hanging Corner between the Tower and wall on the east side of the terrace of the Castle. This meant that in 1752 the medical men in the vicinity had to negotiate out on the moors to obtain the body for post-mortem punishment amidst crowds of up to ten thousand. By 1800 however they could make a more discrete body deal just outside the Castle Walls where average crowds of five thousand were encouraged to accompany the dead body down the hill into the town. The actual post-execution penalty was thus choreographed in three ways. First, the sheriff, his deputy, and the constables, together with the hangman and a designated surgeon, checked for medical death when the body was cut down at the Castle Walls. This was always a preliminary examination to make sure the criminal was not what local people called 'the half-hanged'. It was then carried aloft by the constables to a nearby medical venue where social justice could be seen to be done over the next three days in the presence of the townsfolk (Illustrations 5.1 and 5.2). 


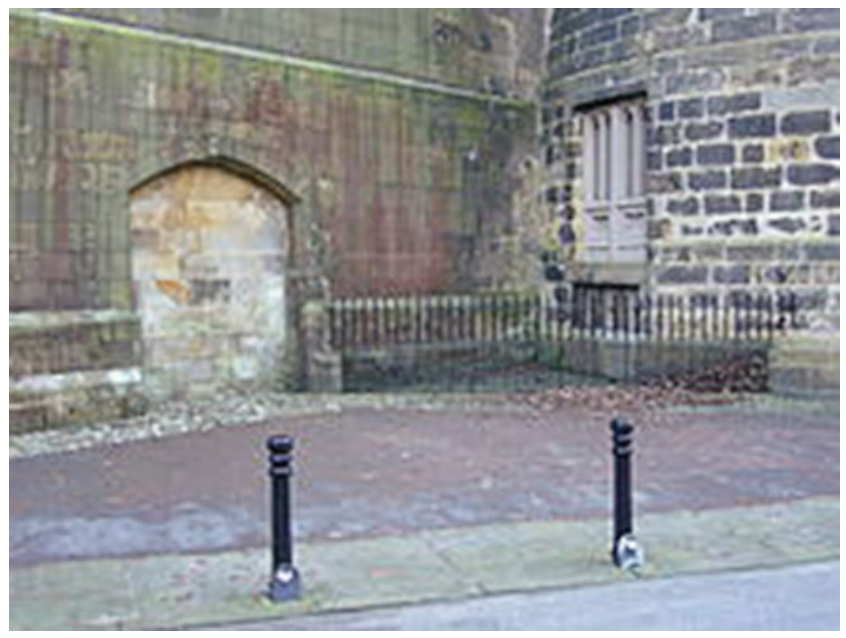

Illustration 5.1 Hanging Corner at Lancaster Castle (photographic image, supplied by the author, 2013). Note: Just outside Lancaster Prison was used as a site of execution for capital offences post-1800 until the Drop Room was opened in 1865. There was originally a drain for all the detritus at the Hanging Corner, now filled in.

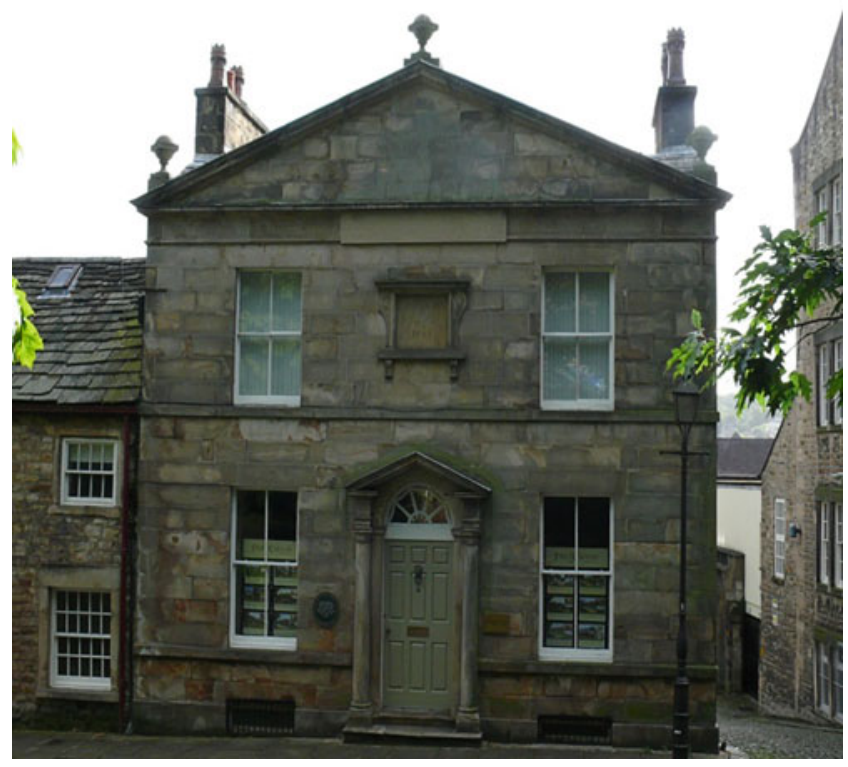

Illustration 5.2 Lancaster Dispensary, Castle Hill, Lancaster (photographic image, supplied by the author, 2013). 
In Lancaster, and towns like it across the North West of England, the primary venue for dissection was a local medical dispensary. At the bottom of Castle Hill some two hundred yards from the gates of Lancaster Castle was a medical space in which by custom criminal corpses were dissected to complete the capital sentence of the Murder Act. When by way of example Ashton Worrall aged twenty-five was convicted of the murder of Sarah McLellon in 1831, his body was executed at Hanging Corner. After basic resuscitation procedures were tried and failed, his corpse by nightfall was taken down the hill from the Castle by the constables to Lancaster medical dispensary. Overnight the medical men monitored his life-signs to double-check medical death at the anatomization stage of the punishment process, and then he was made ready for dissection the next day. John Pickstone explains why this venue came to prominence:

The Lancaster Dispensary was begun by Dr David Campbell, an Edinburgh graduate ... In 1795 both Lancaster and Kendal were prosperous confident towns, not greatly depressed by wars. Beside their dispensaries, each had a relatively new workhouse (Kendal 1769, Lancaster 1787) and these were well kept. Friendly societies, including some for women, had developed since mid-century, and especially during the 1780s. Lancaster had eighteen... and since the male membership of Lancaster societies was over 1,100 , and the number of families in the borough about 2, 000, a high proportion of those families must have been insured against the sickness of their wage earners....By the end of the Napoleonic Wars, Lancaster's trade had stagnated, but in the early 1820s the Dispensary continued to treat between 1, 000 and 1, 500 cases per year... By contemporary standards Lancaster was well-equipped with medical institutions and these enjoyed general support. ${ }^{11}$

Medical dispensaries tended to be built to promote religious duty and a sense of civic loyalty through positive healthcare initiatives. Funded by major manufacturers, amongst townsfolk they promoted social stability. Their charitable rules included free treatments for general illness, epidemics, and industrial accidents because these were not good for business profits, trade cycles or robust public health. The dispensary venue had important medico-legal purposes too. It could be used for a local coroner's court instead of a public house, or act as the designated legal space where post-mortem punishment took place after execution. Dispensaries were generally seen as ideal places to send criminal corpses in the North West because they were very popular and so they became an accessible public 
relations vehicle for the anatomical sciences. Those at Lancaster, Bolton, Halifax, Kendal, Preston, Wigan, and Wakefield, all provided nondomiciliary medical care and were known locally as the 'people's friend'. ${ }^{12}$ If the medical profession in the provinces sought to really gain acceptance of dissection then it made sense to use dispensary facilities to gain popular acceptance of post-mortem 'harm' before the establishment of local voluntary hospitals. The medico-legal fraternity promoted this forum in which local people already felt comfortable, trusted the services on offer, and were encouraged to actively seek a medical note given by a subscriber. They did so aware that their participation in dissections was symbolically about endorsing their deterrence value too, in return for medical help. If elites wanted to get local people talking about feeling a sense of belonging for retribution, then this location was ideally placed to start that official process of crime and punishment.

At Lancaster the dispensary was located in a small town house, a walk downhill of no more than five minutes from the gallows at the Castle. This made the public dissection day an accessible experience in close proximity. The crowd had an opportunity to engage first-hand with the criminal corpse. Most could literally lean over a finger, hand, leg, foot, chest, head, inspecting the cold pallor, smelling the scent of decay, noting the hair colour, length of nails, height and weight, as they walked around the condemned lying dead. Normally they were laid out on a dissection table placed just inside the dispensary front door. Dissecting in a dispensary space like this thus tried to set up a much more interactive, more positive public relations relationship with the local community in terms of post-execution legitimacy. It was also the case that the Old Poor Law discouraged people from becoming claimants around Lancaster fearing that sickness was a long term drain on the parish rates. Local people likewise often resented being sent to, constrained by, or indeed judged within, an expanding voluntary hospital system. In dispensaries, they felt no sense of shame and could participate in the range of services on offer without fear of censure. In other words, dispensaries were seen as more democratic spaces of social justice and increasingly they became conduits for medical services in ways that have been neglected in standard crime histories.

Record linkage work introduces us to those medical men present at the dispensary on the night that Ashton Worall's corpse was carried down from Castle Hill to the Lancaster dispensary after execution on 14 March 1831. Dr. Christopher Johnson (1782-1866) was the honorary surgeon waiting to receive the executed body from the Castle constables. He was 
an ideal choice to undertake the post-mortem work. Johnson was fascinated by the new science of forensic medicine, having already published the well-received The Signs of Murder in New Born Children (1813). George Howson explains that like many provincial self-made surgeons, Johnson was largely self-educated, from a humble background (an orphan child), but ambitious. He concentrated on climbing the career ladder in the vicinity where he could gain a strong financial foothold. ${ }^{13}$ Seeking further anatomical education abroad in Paris or Leyden, or in London, was not economically viable. Instead he had to rely on local connections to improve his reputation and research credentials in the immediate medical market-place. Apprenticed to a Preston surgeon-apothecary, Johnson earned enough to study for his medical degree at Edinburgh before returning to Lancaster to establish his reputation in the North West. His honorary surgical position with the Lancaster dispensary was necessary to attract clients from across the social spectrum. If he did not diversify his income-streams, then he might not survive the cut-throat medical business. In addition to his dispensary work he thus acted as honorary surgeon to the part-time Lonsdale Local Militia and by 1815 held the same position with the newly established House of Recovery in the town. A prominent member of the Lancaster Medical Book Club (1823) and Leeds Mechanic Institute (1824) he was well-networked by the time he raised the lancet over Ashton Worrall.

Standing beside Christopher Johnson in the dissection room was Lawson Whalley (1782-1841). ${ }^{14} \mathrm{He}$ was a Quaker, and honourable Physician to the Lancaster dispensary. Whalley's role was to oversee the dissection in 1831. He was tasked with watching over the knife skills of his surgical colleagues. He too went to Edinburgh to study medicine but coming from a wealthy Quaker family could afford to train for seven years as a physician, qualifying in 1804 . Nevertheless, he found it necessary to attract loyal fee-paying appointments because of the topsy-turvy nature of medical consumers with cash-flow problems. So he secured the position of medical officer to the Eagle Insurance Company, as well as his honorary dispensary position. Whalley soon established himself as the preeminent medical man in Lancaster, seeking election to office, helping to set up the medical services of the local asylum, becoming a magistrate in 1836, and joining the same medical networks as Christopher Johnson. John Pickstone has found that there were often professional tensions between physicians and surgeons in local dispensaries located across the North West connected to Manchester. ${ }^{15}$ Yet, this detailed study has not uncovered such rivalries in the case of Lancaster. Perhaps because it was 
'The Hanging Town' and more bodies became available from the gallows there seems to have been less to dispute about access to, and medical authority over, criminal dissections in the town.

A third medical man present at the dissection of Ashton Worrall in Lancaster dispensary was Dr Jonathan Binns. He was described in the Annual Medical Register as 'Extra-Licensate of the Royal College of Physicians for Lancaster'. ${ }^{16}$ Binns had strong medical connections to Liverpool, being listed as a branch member of the Society for the Abolition of the African Slave Trade in 1788. He also worked for a time with $\mathrm{Dr}$ Currie at the Liverpool dispensary before taking up an appointment as Physician superintendent to Ackworth Quaker School in 1795. At this renowned Yorkshire educational establishment he wrote An Introduction to English Grammar in his leisure hours. By 1807 he had moved jobs to Lancaster Infirmary as an honorary Physician where he became an expert on the treatment of scarletina and appears to have developed a keen interest in child medicine. ${ }^{17}$ Taken together then, these three men had medicolegal jurisdiction over Ashton Worrall's corpse.

Other towns in the North West had been anxious to get hold of Ashton Worrall's criminal corpse, but their requests were rejected. Penal surgeons did not however give up hope of being supplied by Lancaster gallows on the night that Worrall was executed. Lancaster had a policy of doing double and triple hangings, and this meant that there were two other bodies executed alongside Worrall. Those in Preston thus pressed hard to get their fair share. William Worrall aged thirty-eight (the older sibling of Ashton), was an accessory to the same murder of Sarah McLellon of Failsworth near Oldham in Greater Manchester. Although Ashton and William had been hanged together, the Sheriff used his discretionary powers to redistribute the two brothers in death. William Worrall had offended the hangman because he refused to walk quietly to the gallows outside Lancaster Castle. Local newspapers reported that he would not stand still. He was very agitated and aggressively kicked off his shoes, hurling them at the executioner. The Judge had sent for Samuel Haywood the skilled hangman from Ashby Magna in Leicestershire who normally covered the East Midlands area (refer Chapter 2). Even so, local histories stressed that it was no easy matter to do a fast execution of William Worrall. Eventually, with the help of the constables the hangman tied the rope round his neck and he was hanged for over an hour. To avoid any further disruption, and keen to assist other surgeons nearby, William Worrall's corpse was sent to Preston medical dispensary. This outcome reveals how the economy 
Table 5.2 Preston physicians, surgeons and apothecaries, circa 1831

\begin{tabular}{lll}
\hline Preston Physicians & Preston Surgeons & Preston Apothecaries \\
\hline Dr Thomas Cuncliffe & Dr William Alexander & John Fallowfield Snr \\
Dr R Watson Robinson & Dr Edmund Armistead & John Fallowfield Jnr \\
$D r$ William St Clare snr & Dr Edward Briggs & Thomas Fallowfield \\
$D r$ William St Clare jnr & Dr William Farrar & William Gilbert \\
& Dr William Gilberston & James Mounsey \\
& Dr Thomas More & John Taylor \\
& Dr James Swift & \\
& Dr S. Sherlock Thompson \\
& Drs Walton and Lodge & \\
& Dr James Wood & \\
&
\end{tabular}

of supply operated through body-distribution schemes managed by the Sheriff and hangman who consulted medical men across the North West.

Conveniently the Preston dispensary had a discrete entrance in Surgeon's Court just off Lune Lane in the town, and visitor numbers could be controlled. ${ }^{18}$ Yet this was also a public space and one valued by the poor who needed cheap medicine dispensed from its charitable funds. William Worrall's dissection was not a large-scale entertainment but instead it took place amidst ordinary people who congregated into a small room at the front of the building to see, smell, brush past, gaze at, and talk about the bruised condition of the criminal corpse. This type of dissection venue was again all about being in close proximity. It was expected that there would be an accessible viewing of the abnormal criminal reduced to an anatomical normality of bone, skull, and body shell. In this socio-medical space, the labouring poor, industrial workers, people who lived on the threshold of relative to absolute poverty, participated in a spectacle that expressed community and belonging, criminal deviance and what it meant to be the ultimate social outcast.

There were a lot of medical men working in Preston who could potentially attend the dissection of William Worrall in March 1831. Table 5.2 above lists those trading in town. In addition to those listed, a Mr Greenwood acted as dispensary apothecary, Mr Richard Oldfield was his dispensing assistant, and the work of everyone on site was overseen by Dr William St Clare junior, an honorary Physician, and a renowned medical figure in the locality. As Preston was the economic heartland of the district, rapidly becoming one of the richest trading and most expansive towns in industrial Britain, it is perhaps 
unsurprising to find such a crowded medical market-place in operation. The four prominent physicians, ten surgeons and seven apothecaries, together served most of the county of Lancashire. There was thus a competitive atmosphere and high demand for the corpse of William Worrall in Preston. If everyone was permitted to attend the enclosed space-and there was some local debate about this in many localities - there often was not much elbow-room.

Opened on the 25 October 1809, Preston dispensary had treated ' 12 , 239 patients' by 22 October 1817. It was a busy, crowded medical space, described in a History of the Borough of Preston some ten years before William Worrall's body was being dissected inside, as:

This noble edifice has a fine polished stone front, well lighted by eight elliptic and square windows, fronting Fisher-gate, and is palisaded, with two flights of steps up to the main entrance from the street, ornamented with an elevated lamp, for the purpose of giving light, by gas, in the winter time, which considerably embellishes the front, The inside is well planned for the purposes it was built for, consisting of a room for the medicines, with a room on the ground floor [consulting space] and a kitchen below for the matron, together with drawing and other rooms [for dissection], so useful and necessary. ${ }^{19}$

Early histories of the Preston dispensary stress however that until the 1830s surgeons were excluded from practicing from the premises. It was physicians who dominated the medical charity to the chagrin of the surgeons. ${ }^{20}$ This explains how it was that Dr William St Clare junior became a respected physician and leading political commentator in the town. He described election days and execution times as raucous affairs. When working from the dispensary he said he often felt: 'half suffocated and squeezed to a jelly' by the assembled crowds. ${ }^{21}$

John Pickstone observed that from 1821 several surgeons tried to challenge the dominance of physicians like St Clare at the Preston dispensary but their chief motivation for doing so were never made public. ${ }^{22}$ This study's recent finding is that the ten local surgeons (see Table 5.2, Section 2 ) pressed to get official appointments at the Preston dispensary by 1831 because for a decade they had wanted to benefit from the body-delivery scheme controlled by Lancaster Castle. Only it facilitated medical research opportunities and yet they were excluded from local justice that should have come within their official purview. Preston surgeons were not alone in their desire for better professional recognition through improved access to criminal dissections in the North West. Manchester surgeons were equally concerned to get their fair share from the gallows. 


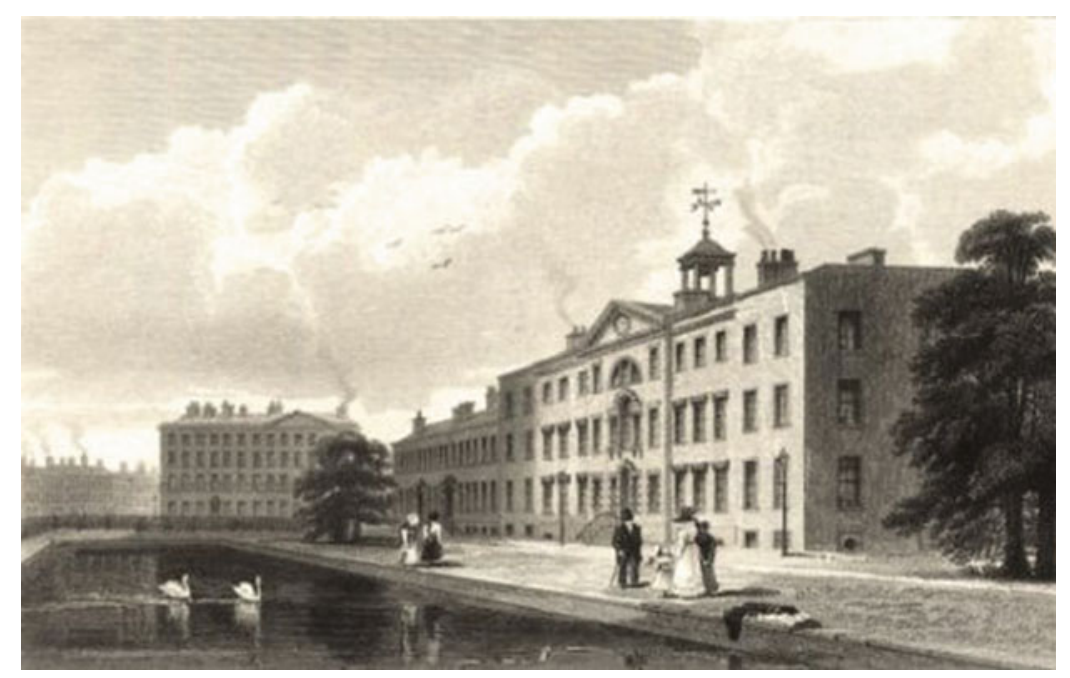

Illustration 5.3 C Wellcome Trust Image Collection, Slide Number L001 1830, Samuel Austin (1831), 'The Manchester Infirmary, dispensary and lunatic asylum', line engraving; Creative Commons Attribution-NonCommercial-ShareAlike 4.0 International License (CC BY-NC-SA 4.0)

There was a third body that was distributed the night that the Worrall brothers were executed, called Moses Fernley. Fernley had been found guilty of a separate homicide, the killing of his five year old stepson at Hulme a town suburb in Greater Manchester. The Manchester Guardian thus reported that although Ashton Worrall died almost instantaneously and William struggled a lot' but in the end 'appeared to suffer very little pain', Fernley's death 'was long and violently convulsed, before life was extinct' ${ }^{23}$ The timing of medical death differed in all three executions and it was troublesome to the very experienced hangman and penal surgeon on duty at Lancaster. Since Fernley had taken much longer to die, and his crime of homicide had been originally committed in Hulme, Samuel Haywood the executioner agreed to send his body back to Manchester. He did so on the basis that post-mortem 'harm' belonged by customary rights to the community in the vicinity of the original murder. Fernley's body was despatched by the coaching express to the Manchester Infirmary, Dispensary and Lunatic Asylum (see Illustration 5.3 above) where the leading anatomist-surgeon Thomas Turner presided over the criminal 
dissection. ${ }^{24}$ The chosen medical venue was not a coincidence. The records of the Lancaster and Chester Antiquarian Society explain that the infirmary had been established in 1752 and moved to new buildings in 1755 along Piccadilly in central Manchester. Here the majority of the sick poor were alleviated on a daily basis through a medical dispensary system. ${ }^{25}$ These arrangements coincided with the Murder Act and so it was logical to use the premises for dissection work too. When Moses Fernley's body became available in 1831 it was returned to a vibrant research and teaching space. Here Manchester anatomists were anxious to prove their credentials to their counterparts at the Royal College of Surgeons.

In infamous murder cases a lot more information has survived about the sorts of dissection venues used and therefore issue of representativeness need to be evaluated. The value of such detailed record-keeping is that it is a useful starting point for retracing body-supply schemes in leading areas like the North West. These can then enable historians to start to build upon a wide range of recent scholarship on healthcare and welfare too. It is feasible for instance to envisage how post-mortem 'harm' fitted more broadly into a local economy of makeshifts. This was organized regionally and looked distinctive as you travelled up or down the country. Steve King's work on 'regional states of welfare' shows that the more West and North you travelled to the Left of the Pennines the harsher the Old Poor Law welfare system became in practice from 1750 to $1850 .{ }^{26}$ Martin Gorsky has equally found that in these same areas there tended to be a greater number of friendly societies because poorer people had to generate alternative ways to save for a rainy day in times of sickness or to bury their dead. ${ }^{27}$ Medical dispensaries (funded from charitable resources) thus became intrinsic to the mixed-economy of welfare in the North West. This backdrop stresses the importance of dissection spaces in ordinary people's lives and why they took on such a symbolic importance in the vicinity.

Before leaving the North of England it is worth exploring briefly the sorts of dissection venues to the right of the Pennines in the North East. In prominent medical places like York and Leeds, the Assizes was held on a regular basis covering the East and West Ridings of Yorkshire. There were similar medical dispensary buildings being used for criminal dissections as those in Lancashire. In manufacturing towns like Halifax, Sheffield and Wakefield, provincial physicians and surgeons were anxious to dissect in community spaces like those in use across the North West. Although therefore Newcastle had its own Surgeon's Hall, it resembled 
the spatial architecture of Edinburgh and London venues, and was thus atypical of communal premises designated for use across the North East. One representative example provides useful context about the setting of an average criminal dissection in northern towns and cities. On 7 February 1817 Michael Pickles and John Greenwood were charged with the robbery and murder of Samuel Sutcliffe. He was killed at a wellknown beauty spot called Hardcastle Crags, near Hebden Bridge, not far from Fountains Abbey estate near Ripon. ${ }^{28}$ In court verifiable evidence was presented which established beyond reasonable doubt that whilst Greenwood had robbed the victim, it had been Pickles who had strangled him with his bare hands in a vicious attack. The Judge decided to make an example of Pickles and ordered that he be hanged at York. He was then taken down, anatomized to check his medical death, and sent by express coach to Halifax dispensary to be dissected in a medical venue not far away from the murder scene. Justice had to be seen to be done locally to make it a community affair. Such new findings reiterate that popularizing criminal dissections was intrinsic to the post-mortem 'harm' of the criminal corpse. It took place in a wide variety of manufacturing towns with busy medical dispensaries in the North of England from 1752 to 1832 .

Moving then down Map 5.1 into Band B (see, Section 1) covering the Midlands reveals what was happening across the central belt of England. In for instance eighteenth-century Derbyshire there were a number of medical gentlemen with provincial standing who were to rise to national importance after the Murder Act. Aspiring men, like Erasmus Darwin the physician who had qualified in medicine at Cambridge, cultivated a large circle of up-and-coming Natural Scientists. Together they founded the famous Lunar Circle based in Birmingham..$^{29}$ Known today as the Lunar Society, historians have seen it as a vehicle for ambitious men who exuded Enlightenment ideals. ${ }^{30}$ Surgeons connected to the criminal justice system were keen to join from across the area.

Membership of this tight-knit group featured dynamic characters like Joseph Wright of Derby. He was a renowned painter whose enquiring mind extended to scientific endeavour. Wright was fascinated by links between engineering design and resuscitation techniques. These were famously depicted in his paintings of The Orrery (1766), Experiment on a Bird in an Air Pump (1768) and The Alchemist in Search of the Philosopher's Stone (1795). From the 1760s he painted those pursing scientific eclecticism like his near-relation Richard Wright the surgeon 
(1730-1814) of Derby (see Illustration 5.4) who operated in the provinces under the capital code. These were the sort of characters that also purchased phrenology heads (see Illustration 5.5) made in porcelain in the nearby Staffordshire potteries (see, also Chapter 6).

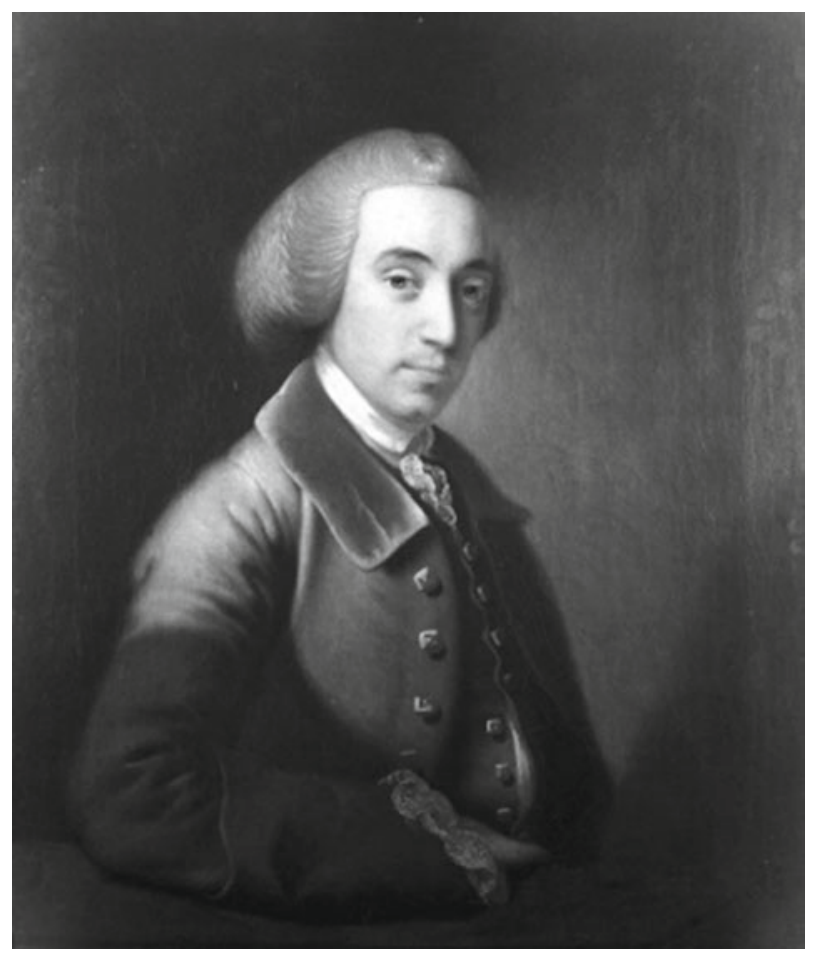

Illustration 5.4 C) Wellcome Trust Image Collection, Slide Number L0013434, Joseph Wright of Derby portrait of 'Richard Wright (1730-1814) surgeon of Derby', oil painting; Creative Commons Attribution-NonCommercial-ShareAlike 4.0 International License (CC BY-NC-SA 4.0)

When therefore it came to establishing the Derby Infirmary and designing its new dissection room, the team of assembled experts was dominated by men with leading medical and scientific interests. All were concerned to improve health and safety for patients, practitioners, and penal surgeons. By the 1820s the 'new sciences' of electricity had really taken hold in Derby. 


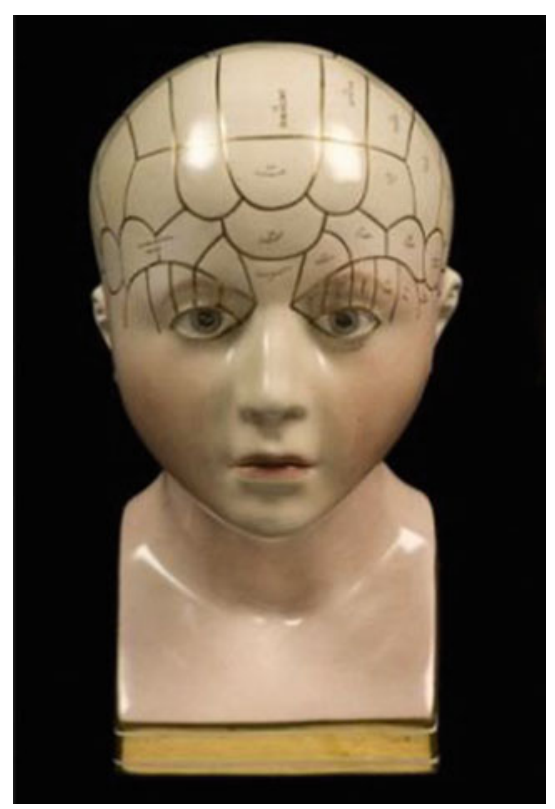

Illustration 5.5 C Wellcome Trust Image Collection, Slide Number L0058695, 'Porcelain phrenological bust, tinted skin colour, divisions labels and numbers marked in gilt, probably in Derby', made at the Staffordshire Potteries early nineteenth century, object held in the Science Museum, A642806, clay cast; Creative Commons Attribution-NonCommercial-ShareAlike 4.0 International License (CC BY-NC-SA 4.0)

It was these sorts of enquiring subjects and minds that also joined the newly formed Derby Mechanics Institute. Access to fresh cadavers was thus one, amongst a number, of medical channels to improve a growing and impressive body of knowledge. In the archives the historical prism of Derby illuminates the sorts of 'natural curiosity' that criminal corpses engendered in the Midlands that was influential elsewhere in England.

Traditionally in Derby town there were three sites of execution for general capital offences-at Nun's Green up to 1807-then at Friar Gate from 1812 to 1828 - and at Derby Jail from 1833 until 1907. Data collected for this chapter confirms that at Friar Gate some 58 prisoners were hanged between 1756 and 1825 covering most of the time period of 
this book. The majority of murderers were sentenced to death at the Shire Hall where the county Assizes was held four times a year. They were then taken outside to the front of the building into a courtyard and hanged. Once the jerking ceased, the condemned body was brought back inside the front door of Shire Hall. Here it was dissected in full public view of the assembled crowd: a pattern of local justice that was repeated across the Midlands. The judiciary decreed that retribution had to be transparent and conveniently located in the vicinity of original criminal trials. The application of the Murder Act essentially expressed local sentiments that there must be a combination of legal, professional, religious, and scientific eyes gathered together in one place for completing the capital punishment rites. One example stands in for many at the time.

Mary Dilkes was convicted of the murder of her bastard child on 29 March 1754. She was conveyed in a cart from Derby jailhouse to the Assizes courtroom at Derby Shire Hall. Found guilty of murder, on pronouncement of the death sentence, she was executed on a new gallows that had been erected outside in the main courtyard of the law courts. In the vicinity, she was one of the first murderers to be hanged like this after the Murder Act. Her case thus set a number of medico-legal precedents about the accepted choreography of punishment rites. The Judge sentenced her to be 'dissected and anatomized' (he refused a pardon). This was done after she was cut down by the hangman and taken just inside the entrance to the left door of Shire Hall (see, images below). ${ }^{31}$ By tradition the designated penal surgeon occupied a house at 44 Friar Gate in the town. Handily, he lived close by to be called upon by the hangman on execution days. Spatially the execution and its post-mortem rituals were therefore aligned carefully into Derby's urban design. Derby Shire Hall, or 'Court of Justice' as it was became known, was thus described as 'long the pride of the Midland Circuit; longer the dread of the criminal and the client; but the delight of the lawyer'. ${ }^{32}$

After 1752 building modifications to the main courtyard reflected closer medico-legal ties. From the street side the gallows was protected by a five foot high wall over which the assembled crowd glimpsed executions (see, Illustration 5.6); later this was replaced by high black railings (seen in Illustration 5.7). The latter was erected for better for crowd control. The railings were strong enough to hold back a mob pressing forward but at the same time afforded a better view of what was happening for those standing at the rear. It was hoped that better visibility 
would stop the crowd rioting. The 'Derby Dissection Door' of the Shire Hall building (see, Illustration 5.8) was regarded as the equivalent of the 'Under-door' at London's Surgeon's Hall, but locally it was left open to everyone assembled to see the condemned being carried inside. Postexecution, the crowd were permitted to flood through the iron-gates and walk around the criminal corpse. Surviving contemporary engravings confirm that this was a busy social space. The courtyard-design outside was used for concerts, plays and gatherings, as well as the Assizes. When Derby's New Assembly Rooms were built in 1714 the building became an exclusive Crown Court. This was when an inn, wine vaults and stables were added to the left side in 1795 and judges' lodgings to the right flank around 1811 , eventually creating a u-shaped enclosure. The entire Bloody Code could be self-contained inside the ready-made facilities.

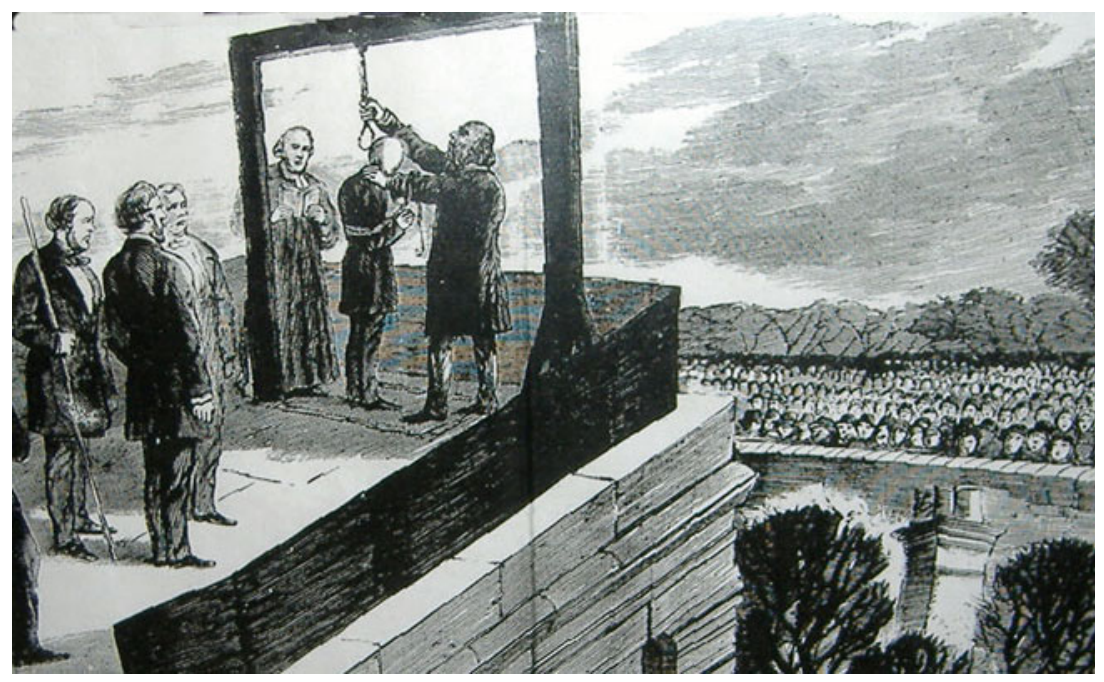

Illustration 5.6 (C) http://www.capitalpunishmentuk.org/derbygaol.html, 'Derby Gallows', woodcut, late-eighteenth century [cross-reference Sketch 5.1] showing walled off area, academic fair use made of open access image; Creative Commons AttributionNonCommercial-ShareAlike 4.0 International License (CC BY-NC-SA 4.0) 


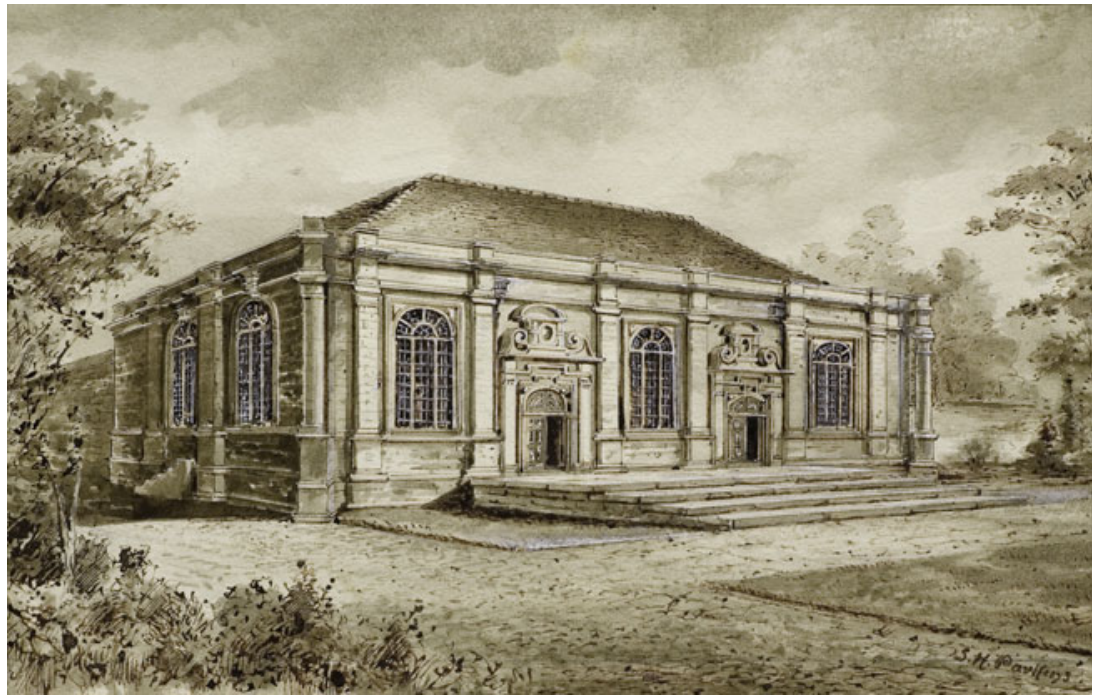

Illustration 5.7 C Picture the Past Digital Images Collection, Derbyshire County Council, Derbyshire Record Office, IMAG 300050, from a painting by S. H. Parkins C. 1800, image can also be viewed at http://www.capitalpunishmentuk. org/derbygaol.html, 'Derby Shire Hall and Assizes Court', woodcut, late-eighteenth century [cross-reference Sketch 5.2]; Creative Commons AttributionNonCommercial-ShareAlike 4.0 International License (CC BY-NC-SA 4.0)

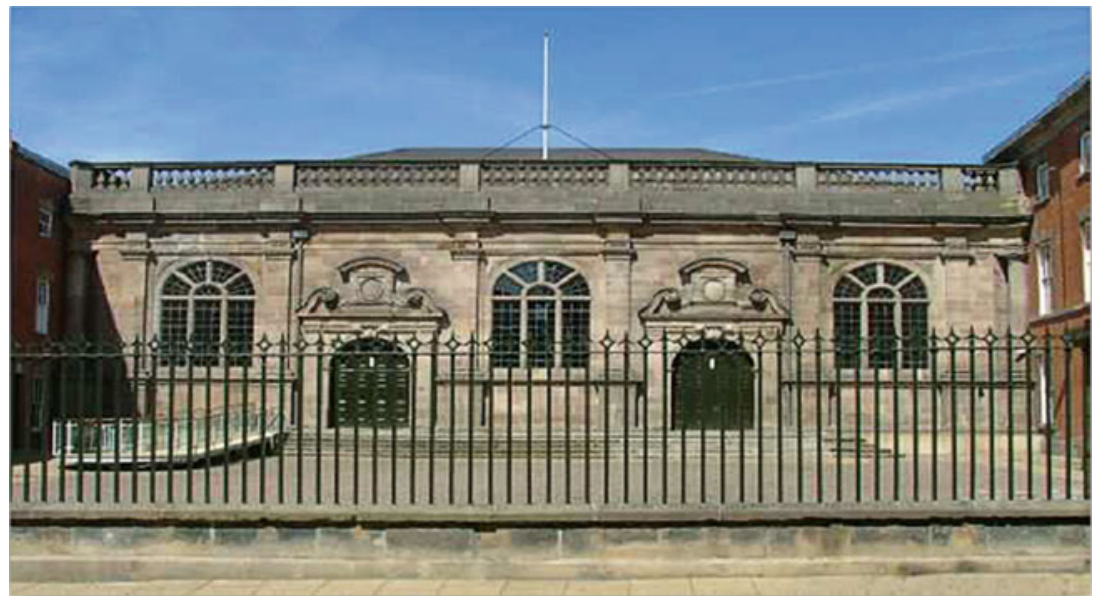

Illustration 5.8 Derby Magistrates Court, located at Old Shire Hall, Derby Town, Courts of Justice, (photographic image supplied by the author, 2013). The door is to the left 


\section{EXECUTION OUTIDE NOTTM SHIRE HALL.}

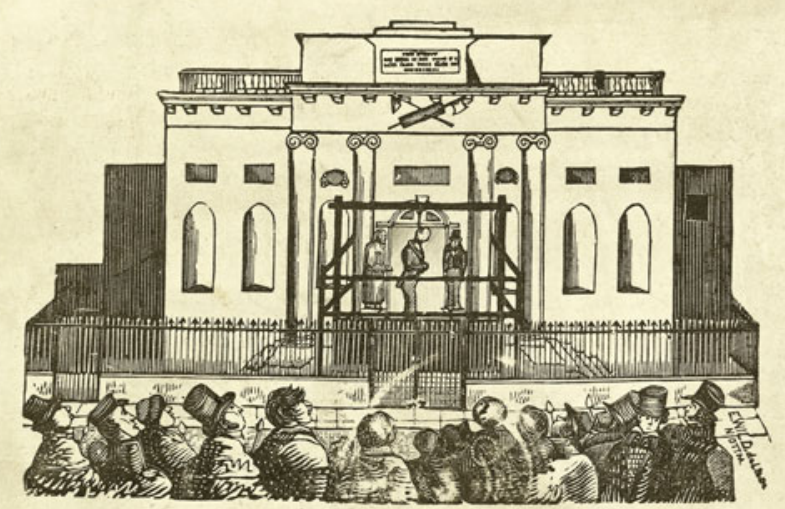

PRINTED FROM WOOD BLOCK CUT BY E.WILDD, dGIET, ORIGINAL BLOCK IN POSSESSION OF A.C.VICE, PRINTER, NOTTM -

Illustration 5.9 C Picture the Past Digital Images Collection, Nottingham City Council, Nottingham Record Office, NTGM 015347, image can also be viewed online as 'Nottingham Assizes, Shire Hall, Gallows' at http://www.nottshistory. org.uk/articles/shirehall.htm, woodcut sketch of public hanging; Creative Commons Attribution-NonCommercial-ShareAlike 4.0 International License (CC BY-NC-SA 4.0)

Since Derby did not have an infirmary or public dispensary until 1810, the chosen medico-legal setting at Shire Hall was a convenient and commodious place. ${ }^{33}$ This was similar to Nottingham where a gallows was constructed in front of the Shire Hall for the same ends of local public justice (Illustration 5.8 depicts the Derby location today, compared to a similar contemporary Illustration 5.9 at Nottingham above).

Turning then to the actual execution day, new source material reveals that Derby anatomists were keen to establish that heart-lung failure was not a reliable indicator of medical death on the gallows around 1810 . Thus after a typical execution a hinged table was brought into Shire Hall and placed just inside the left-hand door. It was crude in design but could be carried and the rough wood washed down easily. The top was a basic front door-design that detached from its pedestal. At one end was a headshaped hole for a bucket to catch any bodily fluids. In the recess, brain 


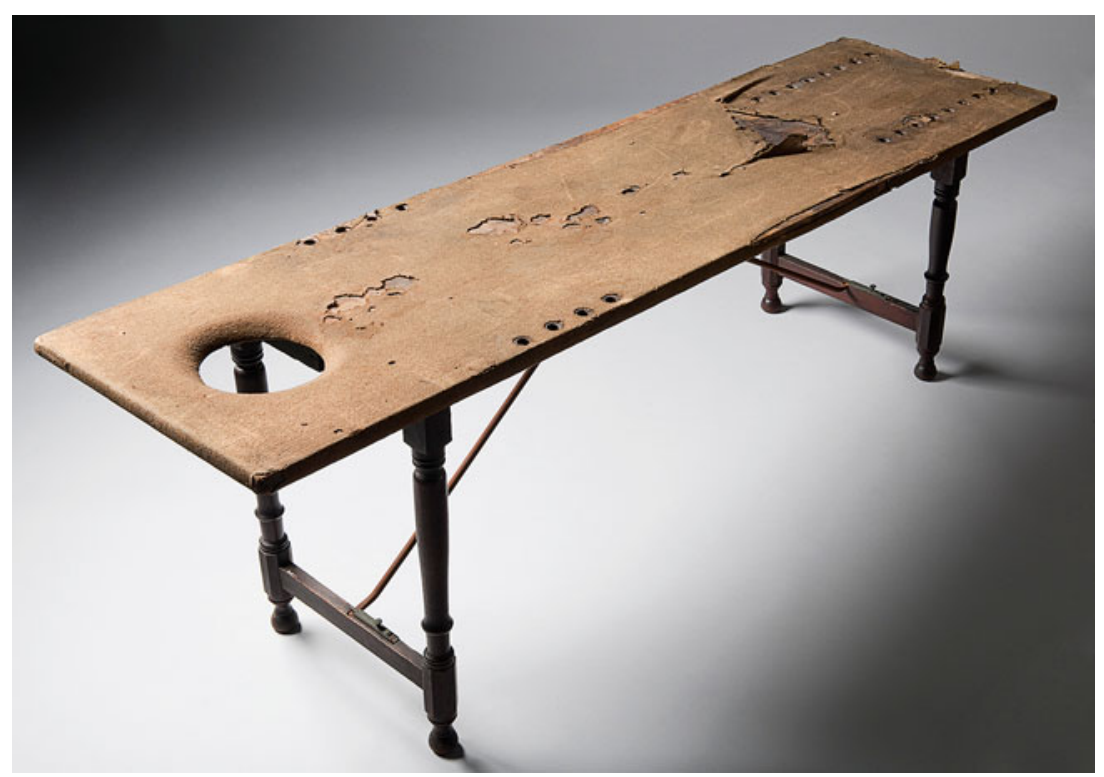

Illustration 5.10 (C) Science Museum, Science \& Society Picture Library, 'eighteenth to nineteenth century dissection table', Image 10572151, circa 1750-1870; used in early modern provincial anatomy schools, dispensaries and voluntary hospitals. Note: image also used at Museum of London exhibition, 2013; Creative Commons Attribution-NonCommercial-ShareAlike 4.0 International License (CC BY-NC-SA 4.0)

work was done once the skull top was sawn off. Nail marks down the table side indicated where pins were put into the arms to keep them in the right position or rope was used to tie down the limbs, especially once rigor mortis set in. Anatomists generally preferred to elevate the lower limbs. They did this by placing them at right angles to the body in a prone position (face up in this instance) usually with the feet placed flat, again nailed or tied down on the bottom of a portable table, or in detachable stirrups. Muscles of the thighs and calves were exposed forward in a large triangle for dissection. The table design was thus basic but simple to handle if the 'mob' decided to riot (Illustration 5.10). The cross bar underneath could be flicked up with a shoe, folded vertical, and carried or transported by hand or cart. It was an ideal length to fit in most anatomical spaces-about seven feet in length-but narrow being just two planks width—not more than three feet wide—often held under 
the shared ownership of coroners and penal surgeons. It generally stood by the banks of a river in drowning cases, was propped open under suicidal hangings, and yet accessible to crowds that demanded to be included in the post-execution spectacle. Onto this innocuous piece of anatomical furniture some of the most notorious criminals were brought to justice in Derby and provincial places like it. Comparing and contrasting 'hangingtowns' in the Midlands with those in East Anglia is instructive about the basic environment and equipment used everywhere.

In the central Midlands belt, the medical fraternity in places like Derby, Nottingham and Leicester, were competing with colleagues in Cambridge, Bury St. Edmunds, and Norwich, for their share of an expanding medical market-place. Their chosen dissection venues were Shire Halls in which Assizes courts were held too. Medico-legal matters were however then transferred to newly-built infirmaries. Some had been constructed around the time of the Murder Act, with many more becoming established in the 1810s and 1820s. These new venues afforded a more medicallyfocused space (still open to the general public) in which to view the criminal corpse across provincial settings in Band B on Map 5.1. That did not however lessen the symbolic importance of opening up bodies at Shire Halls or elsewhere across East Anglia. If anything it made them of greater symbolic importance, especially once more people could squeeze inside purpose-built but smaller-scale voluntary hospital morgues known as deadhouses. In by way of example the famous case of William Corder hanged for the Red Barn Murder and taken to be anatomized at the Shire Hall in Bury St Edmunds a lot of spatial anatomical detail was reported about the change-over of venues in the local press. This was done to reassure the general public that such a notorious murderer had received the full legal penalty. The Morning Post stated for instance on 14 August 1828 that:

About half an hour after the execution the body was removed to a private room in the Shire Hall where Mr Creed, the county surgeon, assisted by $\mathrm{Mr}$ Smith and Mr Dalton, made a longitudinal incision along the chest, as far as the abdominal parts, and deprived it of its skin, so as to exhibit the muscles of the chest... They were going to move him to the hospital but this was objected to by Mr Foxton (the completer of the law) until he had first stripped him of his trousers and stockings. ${ }^{34}$

The newspaper reporter explained that the first anatomical duty was to try to accommodate ' 5,000 ' people determined to accompany the body on its post-execution journey. Their actions reflected a strong public reaction to the infamous murder. The reporter continued: 
The anxiety to see Corder's body was as great as at his execution: crowds flocked around the doors. He was put in the Nisi Prius Court, and the people entered at one door and departed at another; he was placed on the table, and, with the exception of his trousers and stockings, he was naked; there was not much change of countenance, but it appeared there was a great affusion [sic] of blood about his throat. Such was the anxiety to see him that we heard several females boasting that they had been in to see him five times after his head was shaved! ${ }^{35}$

These two excerpts confirm key findings already presented in this book. There was a lot of 'natural curiosity' amongst the crowd participating in a renowned murder case after the body was cut down from the gallows. The accounts also suggest that local people were determined to accompany the corpse from the gallows. In terms of the choreography of the capital sentence, one third (legal death) took place on the hangman's rope but two thirds of the indictment, anatomization (medical death) and dissection (post-mortem punishment) happened elsewhere. If the execution was then a spectacle, what happened next was a thrilling encore for the crowds assembled at Shire Halls everywhere.

In East Anglia the procession to dissection venues was a very important but still understudied aspect of the Bloody Code. The extracts cited in the case of Bury St Edmunds confirm that again there were practical differences between the first anatomical cuts and a full-scale dissection. And, once more, we can see this in the transitional use of Shire Hills to voluntary hospitals in which to do post-mortem punishments. Local newspaper reports thus contained a candid admission that there was a 'completer of the law' and this happened post-execution. In the Red Barn case the hangman Mr Foxton had a customary right to take the prisoner's trousers and stockings but only once a preliminary check had been made for life-signs by Mr Creed the county penal surgeon and his pupil assistants. Both officials were responsible for checking medical death had occurred because sometimes it did not. Of note too is the physical attraction that a shaven corpse had for a female audience. Corder was a dangerous alpha male lying dead on a table in the courtroom causing quite a stir of mixed emotions for the assembled crowd. This seems to explain why the location of the initial anatomization took place in a room of Shire Hall before the body was moved to the county infirmary for dissection the next day. Of necessity, there were two different medico-legal checking mechanisms to ensure a public death: one confirmed death, the other harmed the condemned in death. Each was staged separately to emphasis their separate medico-legal functions. In the meantime, the Shire Hall 
door was left open to visitors until 6 pm when the doors were closed. A local reporter thus remarked that:

We heard that his mother intends to apply for his body after being dissected; but this we trust she will not do, as it must only pain her already too much of agonized feelings to meet a refusal. It is the intention to preserve his skeleton. He is the first body that ever was dissected at the Infirmary. ${ }^{36}$

The reporter was determined to get the full post-mortem story and so he followed a select group of medical men to the Suffolk General Hospital ${ }^{37}$ in the town the following morning, the crowd having satisfied themselves that Corder was 'truly dead'. The next day, Tuesday at 12 noon, there was:

A great concourse of medical gentlemen, with a crowd of students, assembled at the county hospital to witness the dissection; among whom were all the practitioners round the neighbourhood and even some from Norwich \& Cambridge \& c...

$\mathrm{Mr}$ Creed junior assisted by $\mathrm{Mr}$ Smith and Mr Dalton, commenced the operations; they firstly minutely dissected the muscles of the chest, and having elevated the sternum, and examined the lungs, they took out all the intestines, all of which appeared in a most healthy state. From the formation of the chest, it did not appear that Corder would have been a likely subject for pulmonary affection. The Medical Students heard demonstrations about the respective parts... There were some Italian artists there who took two or three casts of his head and also a celebrated Craniologist who informed us that the organs of 'Destructiveness and Secretiveness' were strongly developed..$^{38}$

There is one final detail worth noting about William Corder's postexecution rites. His case caused such a sensation that canny booksellers brought out remarkably detailed accounts of his material demise. These commentators explained that there had recently been a minor but important legal change that impacted on the body-supply of corpses to the surgeons. The passing of $A$ Bill entitled an act for the consolidating and amending the statutes in England relative to offences against the person 1828 (255) [9 Geo. IV.], changed how judges issued legal warrants for criminal corpses. The anatomical fate of bodies to be dissected was now declared on an official warrant when the death penalty was pronounced in court in cases of convicted homicide. The corpse could not be moved until this was done especially in cases when an offensive weapon, like pistols in the case of William Corder, had resulted in murder. The warrant had to state 
explicitly the designated dissection venue. This official piece of paper, akin to a post-mortem passport, had to accompany the body until it reached the grave. William Maginn's popular book thus explains:

The warrant for Corder's execution differed slightly from the form in which former warrants for the execution of murderers had been drawn up. The alteration was made in consequence of Lord Landsdown's late Act for Malicious Injury to the Person. The old form of the warrant merely ordered the body to be given to the surgeons to be anatomized and dissected; the present form appoints the hospital at which the dissection will take place. ${ }^{39}$

Though it seemed some time off, this pivotal procedural change was part of a much bigger trend to create a body supply system that would expand when the poorest became staple subjects of the dissection table after the Anatomy Act.

Meantime in small country villages residents were equally very interested in criminal dissections across the Midlands and East Anglia. In an example that is typical of what tended to happen in remoter country areas, when Elizabeth Morton was executed for murder on 6 April 1763 the judge decreed that her body had to be punished at the actual site of the homicide she had committed. This was in a village called Calverton about seven miles north east of Nottingham on a small tributary of the Dover Beck. There Morton was laid out for inspection, anatomized on day one, and then dissected to the extremities for two days in full public view. The official report said that 'her body was dissected by a surgeon [unnamed] at Calverton and the public curiosity awakened all the curiosity of the surrounding villages who flocked in crowds to the back premises of the surgeon's house'. ${ }^{40}$ It was also reported by those present that 'her features were rather attractive than repulsive: she was strongly made, and tall, considering her age...18'. What was left, less than two-thirds, was buried in a common grave at Sutton-in-Ashfield. We see the same trend in the West Country.

In Map 5.1, Band C, when John Anderson, a constable, apprehended Elizabeth, known as Betty Marsh, aged 14 on 21 January 1794 for the murder of her grandfather there was great excitement in the Dorset countryside. ${ }^{41}$ Betty thumped John Nevill of Mordern over the head with a blunt instrument whilst he slept in bed. He died that night from his fatal injuries. Betty was charged with homicide, tried and convicted. She thus became the first person to be hanged at Dorchester County jail on 17 
March 1794. The question was where could her body be 'dissected and anatomized'? Bath city was a renowned medical market-place awash with surgeons of all descriptions, so too was Bristol, a port city. Yet both were too far away. The corpse would be stinking by the time it got there. It was spring, St Patrick's Day, the turn-pike roads were very muddy and in a cart it would take two good horses a 2-3 day journey. On the other hand, this was a young girl and therefore a valuable anatomical specimen. John and Philip Coombs, surgeons of Dorchester, were on standby to benefit from a rare, but exciting opportunity to take home the criminal corpse of Betty Marsh for their personal research at their domesticated business premises.

Moving down into Cornwall meantime we see further examples of this pattern of punishment. In 1814, Williams Burns aged twenty-one, an Irish army recruit of the Royal artillery, murdered a sailor named John Allen after a drunken night in a public house in Penzance. Burns was committed to Bodmin gaol, tried and found guilty of homicide at the Assizes for the Western Circuit at Launceston. ${ }^{42}$ A surviving bill in the Sheriff's cravings reveals the expenses connected to his punishment:

\section{Gaoler's Bill:}

Paid Deacon his Bill on executing William Burns

$\begin{array}{rrr}£ & \text { s } & \text { d } \\ 4 & 14 & 6 \\ 2 & 2 & 0 \\ 0 & 6 & 0 \\ 1 & 8 & 0 \\ 1 & 5 & 0 \\ 0 & 10 & 0\end{array}$

J Chapple sending a waggon to Bodmin for the Drop

Turnpike

4 Guardsmen 1 day @ 7/- each

J Chapple and Horse 1 day

Attendance of William Burn's Executioner

Total

$1056^{43}$

Quite often in Cornwall criminal corpses were handed back to gaol surgeons to punish post-mortem because of the rate that bodies rotted at. This sets in context why a gaoler's bill was being reclaimed on this occasion. If Burns' body had been sent back to Penzance where he committed the murder then the only fast means of transport was according to the Cornwall Visitor's Guide of 1814 to catch 'the great mail coach from London-to Falmouth, Penzance \&c'. ${ }^{44}$ It advised, 'Quitting Bodmin the road proceeds to Truro, twenty-two and a half miles, passing over the gorse-moors (eight miles in length)... The road to Penzance branches off between Truro and Penrhyn' through lots of small villages. But this meant covering a total distance of almost forty-eight miles between execution at noon and nightfall. On those main routes resurfaced across Cornwall in the 1790s the mail-coach 
travelled on time, but on minor roads the carriage wheel often got stuck in the mud and pot-holes. When bodies were handed over to penal surgeons they thus tended to be dissected by prominent figures in town politics like Dr Coryndon Rowe, senior alderman and magistrate, who was living in Launceston with a business premises close to the Assizes execution site. ${ }^{45}$ William Burns however was dissected by Joseph Hamley, surgeon and coroner for the Eastern district of Cornwall since a decision was taken by the sentencing judge for reasons of convenience to dissect him at Bodmin gaol where he had been remanded pending trial. ${ }^{46}$ In out-laying rural areas involving provincial anatomical studies after the Murder Act, location mattered. This was why the economy of supply in criminal corpses in the West Country and remoter counties looked different compared to elsewhere.

\section{CONCLUSION}

English hangmen are not celebrated for their medicinal abilities in histories of crime and justice under the Murder Act: a general observation recently substantiated by Owen Davies. ${ }^{47}$ Many home-grown executioners were inefficient and lacked a basic knowledge of death's infinite variations compared to their European counterparts. All manner of anatomical features were confusing about the executed-'age, body size, recurring disease patterns, ambient body temperatures, air movement', and apparent manner of death. ${ }^{48}$ Yet, the medical fraternity increasingly relied on the co-operation of those confused by death's dominion. They handled a chain of supply needed to carry out official criminal dissections in English counties. The geographic reach of these medico-legal networks and their basic punishment provisions have not been documented on location, until now. This chapter has provided for the first time a model of supply mechanism under the Murder Act. It has correspondingly shown an historical appreciation of the spatial architectural setting of dissections and their actual placement in communities. That research has revealed that whilst the state increasingly sought to limit the crowd's interaction with medico-legal officials at the execution site itself, they did the reverse at local dissection venues. This outcome better explains why Simon Devereaux for instance has found that scaffolds were being built much higher by the 1790 s. $^{49}$ This physically distanced the crowd from the hangman and increased the theatrics of the punishment event. But that change of practice did not happen in medical isolation. In terms of crowd control, the forces of law and order could afford to be more distant because a change of execution rituals was accompanied by a subtle shift in 
the legal performance of a medical choreography in situ by 1800. Crowds still came to see, be seen, and talk about the punishment spectacle at the hanging-tree. They accepted however more detachment from the punished criminal in return for greater access to the corpse about to be opened up to public inspection in a dissection space in their community centres. The execution event thus became a case of less is more, as Devereaux observes, but this was because what came afterwards was made more accessible and high profile. It was now in the purview of crowds assembled to see and be part of a process of post-mortem 'harm' in the vicinity. Over the long duration then the number of murderers sentenced to death declined historically, but this meant that criminal dissections had to have a more symbolic placement in provincial English society to be as effective. The four punishment zones identified in this chapter set in context where this happened, why a particular location was medically chosen, and thus we see anew the different layers of spatial meaning created.

In the Midland's heartland voluntary hospitals were being built at a rapid pace in England. They were displacing medical dispensaries by offering more specialized surgical services in expanding market towns by the nineteenth-century. The journey of the criminal corpse from court-room to dissection venue reflected this local medical reality. This book's central finding is that post-mortem 'harm' was always located in public spaces in which it would gain greater acceptance by a wide cross-section of the community between 1752 and 1832. In the North of England medical dispensaries were generally used, whereas Shire Halls were occupied in the Midlands and across East Anglia up to 1800. Elsewhere either a purpose built anatomy theatre in Edinburgh, Newcastle or London was refurbished. Meanwhile across large swathes of Devon, Somerset and Cornwall criminal dissections were more variable, taking place in Exeter at a voluntary hospital because it was one of the earliest built in the country, and likewise at Bath and Bristol. By contrast in the rural hinterland of Dorchester and Launceston we find the domesticated business houses of local surgeons and a local gaol being commandeered for use. Once voluntary hospitals were built everywhere by the 1820s the majority of criminal dissection work was transferred there because that made sense as teaching facilities expanded in London and large provincial cities like Birmingham and Manchester. Changes to judges' warrants, which ordered the criminal body to be moved to a specified local hospital for dissection, reflected a gradual bureaucratic restructuring and systemization of the post-execution ritual. Although it was not foreseen or intended at the time, medico-legal 
officialdom was making advance preparations to accommodate what was to become a national system of body supply. It was one connected intimately to healthcare and welfare provision in the provinces, and this was one of the Murder Act's more subtle medical legacies that historians of the early modern era have missed. The spatial alignment of post-execution rites and their physical placement was accommodated by an Old Poor Law infrastructure of small medical dispensaries and public infirmaries. These then expanded their service provision; so much so, that the poorest in society needing basic healthcare, but dying from common diseases of poverty and financial privation, could be made to supply the dissection table by the time of the New Poor Law and its Anatomy Act in the $1830 \mathrm{~s} .{ }^{50}$ The Murder Act facilitated then a lot of medical enterprise. It enabled surgeons to find ways to overcome their supply issues in practical ways. They aligned with health and welfare facilities, peopled by a wide cross-section of the community; some later came to regret their 'natural curiosity' for medical enlightenment that would in turn exploit their impoverishment.

There is no doubt that Surgeon's Hall in London was an iconic venue for criminal dissections under the Murder Act. Its infamy and longevity has however been overstated. The data-set on body supply trends shows that only 16.29 per cent or 147 bodies of the total number of 908 criminal corpses supplied officially from the gallows actually ended up being dissected there. This was double Simon Chaplin's original estimates; nevertheless the majority of condemned bodies were dissected before 1800 . This trend sets again in context the lacklustre reputation of the London Company from the 1790s. By the early nineteenth-century the dominance of body supply from the provincial gallows was a meaningful occurrence in the majority of English counties. Ranking suppliers on three levels has revealed 'the hanging-towns' that predominated and the locations where a surgeon could aspire to do original criminal dissection work outside the metropolis. Wherever those punishments took place they were always carefully orchestrated in early modern England. Many provincial postmortems were marked by distinctive dissection work. Inside the system ambitious medical men congregated together in towns like Lancaster, Preston and Wakefield. Fewer bodies came to Derby but when they did crowds took a great deal of interest in and were active participants, fascinated by heart-lung-brain research It is time then to get closer to this hidden anatomical world to engage with the disintegration of the criminal corpse, its career-making opportunities, and the subsequent remaking of the material afterlives of the condemned throughout England. 


\section{Notes}

1. Henry Wilson (1822), Wonderful Characters, Comprising Memoirs and Anecdotes of the Most Eccentric Characters, Volume 3, (Boston, Lincolnshire: N. H. Whitaker), pp. 132-3.

2. Royal College of Surgeons Collections, MS0396, Correspondence of Messenger Monsey, c. 1732-1788, quote by his obituary writer ' $\mathrm{Mr}$ Wadd'.

3. Florence and Kenneth Wood eds. (1992), A Lancashire Gentleman: The Letter and Journals of Richard Hodgkinson 1763-1847 (Stroud: Allan Sutton Press), entry 6 March 1828, p. 338.

4. Sherriff Cravings, circa 1752-1832, E389-243 to E389-254; 90-147 to 90-169, primarily used to compile database of corpses sent for dissection (individual cases, cited in endnotes).

5. Of the 908,15 bodies came from the admiralty and were executed by naval authorities at execution dock.

6. See, Appendix, for list of bodies acquired, in, Simon Chaplin, (2009), 'John Hunter and the Museum Oeconomy [sic], 1750-1800' (unpublished $\mathrm{PhD}$, King's College London).

7. London is the only place with a $150+$ body-count category, by virtue of its size, and court system.

8. Refer, Peter King (2010), 'The Impact of Urbanization on Murder Rates and on the Geography of Homicide in England and Wales 1780-1850', Historical Journal, Vol. 53, 1-28.

9. There were further legal changes to Assize jurisdictions in 1873 and 1971. The Queen remains however Duke of Lancaster. The Duchy's continued importance is recognised by the appointment of a Chancellor of the Duchy of Lancaster by the Prime Minister with a seat in Cabinet today.

10. The architectural design can be viewed online at: http://www.britishhistory.ac.uk/vch/lancs/vol8/pp4-22 [accessed 28 July 2015], taken from 'The parish of Lancaster (in Lonsdale hundred): General history and castle', in A History of the County of Lancaster: Volume 8, edited by William Farrer and J Brownbill (London, 1914), pp. 4-22.

11. J. V. Pickstone (1985), Medicine and Industrial Society: A History of Hospital Development in Manchester and its region, 1752-1946, (Manchester: Manchester University Press), pp. 65-6.

12. See, Hilary Marland (1987), Medicine and Society in Wakefield and Huddersfield 1780-1870, (Cambridge: Cambridge University Press).

13. George Howson (2002), 'The Lancaster Doctors: Three Case Studies' in Sue Wilson and Jenny Loveridge eds. (2002), Aspects of Lancaster: Discovering Local History, (Barnsley: Wharncliffe Books), chapter 5, pp. 53-63. 
14. Refer for career highlights, Susan Wilson (2002), Aspects of Lancaster: Discovering Local History, (Barnsley, South Yorkshire: Wharncliffe Books), pp. 59-61.

15. See, general context in, Pickstone, Medicine and Industrial Society.

16. See, Anon (1811), The Royal Kalender or Complete and Correct Annual Register for England, Ireland and America for the Year 1811, and so on, (London: J. Stockdale), p. 304.

17. See for example, Jonathan Binns (1807), 'Letter to Dr James Hamilton, Senior Physician to the Edinburgh Royal Infirmary on the Cure of Scarlatina, from Physician Lancaster', Edinburgh Medical and Surgical Journal Vol. 3, (April), 135-44. He wrote against purgative medicine for children with scarletina.

18. http://lanternimages.lancashire.gov.uk/index.php?a=advanced\&s=item\&key=XYToyOntzOjY6IkNPTE9VUiI7czoxMDoiTW9ub2Nocm9tZSI 7czo2OiJNRURJVU0iO3M6MTg6IlBob3RvZ3JhcGhpYyBwcmludCI7 $\mathrm{fQ}==\& p g=70$ [accessed 28th July 2015], Digital Collections, Lancashire Lantern, Lancashire County Council, Record Number 615, 'Old Dispensary, Surgeon's Court, Lune Street, Preston', image taken circa 1937 of the remaining building. See also, Lancashire Archives, Preston Dispensary Records (1809-1866), Accession 5512, HRPD/1-9, NRA 49305. It cannot be reproduced in this book as its copyright is uncertain.

19. Marmaduke Tulket (1821) A History of the Borough of Preston, (Preston and London: P. Whittle). p. 80.

20. Pickstone, Medicine and Industrial Society, pp. 65-6.

21. Lancaster Record Office, MSS, DDWh/4/99, Whittaker of Simonstone.

22. Pickstone, Medicine and Industrial Society, p. 70.

23. See, wide coverage in, The Manchester Guardian 19 March 1831 and The Manchester Times and Gazette, 19 March 1831 and the Lancaster Gazette and General Advertiser 19 March 1831.

24. E. T. Hurren (2011) Dying for Victorian Medicine: English Anatomy and its Trade in the Dead Poor, 1832-1929 (Basingstoke: Palgrave), chapter 7, recounts his dissection work. See also, W. J. Ellwod, A. F. Tuxford eds (1984), Some Manchester Doctors: A Biographical Collection to Mark the 150th anniversary of the Manchester Medical School 1834-1984 (Surrey and Manchester: Unwin Brothers), pp. 75-6. His career path represents the eventual ascendancy of provincial medicine over its metropolitan counterpart. Turner (1793-1873) was a much travelled and well educated man. He was considered to be a leading medical figure in Manchester, renowned for his commitment to improve medical education standards in the North of England. By the time that Moses Fernley's body had become available in 1831, he had established himself as one of the most engaging surgeons in the North West. 
25. W. Farrer and J. Brownbill (1911), 'The city and parish of Manchester: Introduction', in A History of the County of Lancaster: Volume 4, (London: Victoria County History Series), pp. 174-187-http://www.british-history. ac.uk/vch/lancs/vol4/pp,174-187 [accessed 23 January 2015] cites that: 'The Infirmary was first established in Garden Street, Shude Hill, in 1752, and removed to new buildings in Piccadilly (then called Lever's Row) in 1755. In front of it were the old Daubholes, afterwards transformed into a piece of ornamental water, with a fountain; this was removed in 1857. A lunatic asylum was added in 1765 , public baths in 1781, and a dispensary in 1792. The building was refaced with stone about 1835. The lunatic asylum was removed to Stockport Etchells in 1854. Lever's Row was so named from the estate and town house of the Levers of Alkrington': information taken from Lancaster and Chester Antiquarian Society Records, Vol. 20, p. 238.

26. S. A. King (2000), Poverty and Welfare in England 1750-1850 (Manchester: Manchester University Press).

27. Martin Gorsky and Sally Sheard (2006), Financing Medicine: The British Experience since 1750 (London: Routledge).

28. The case has been reconstructed from two key sources: Anon (1830), Yorkshire oddities, incidents and strange events, volume 1 (York; private publication), p. 266 and 'Trials: Lent Assizes York', The York Herald and General Advertiser, Issue 1386, March 22nd 1817, pp. 1-2. A contemporary history of the Halifax Dispensary can be found in John Crabtree (1836), A Concise History of the parish and vicarage of Halifax, in the county of York, (Halifax: Hartley and Walker publishers), p. 346.

29. Jenny Uglow (2002), The Lunar Men: Five Friends whose Curiosity Changed the World (London: Faber and Faber).

30. Peter M Jones (2009), Industrial Enlightenment: Science, Technology and Culture in Birmingham and the West Midlands, 1750-1820 (Manchester: Manchester University Press).

31. Stephen Glover (1829) The history of the county of Derby, drawn up from actual observations and the best authorities, (Derby: Henry Morley and son) p. 615 .

32. William Hutton (1817), The History of Derby: From the Remote Ages of Antiquity (London and Derby: Nicloas, Son, and Bentley), p. 32.

33. Desmond King-Hele ed (2007), The Collected Letters of Erasmus Darwin (Cambridge: Cambridge University Press), p. 575, note 1, explains that William Strutt ran the infirmary and was a close friend of the Darwin family.

34. The Morning Post 14 August 1828 carried extensive reports of the execution and post-execution events and the reaction of the early modern crowd over several days.

35. Ibid. 
36. Refer, endnote 34 above.

37. Suffolk General Hospital was founded on 4 Jan. 1826; after 1832 it was called the West Suffolk Hospital.

38. Refer endnote 34 above.

39. William Maginn (1831 edition), The Red Barn a Tale Founded on Fact, (London: John Bennett Publishers), p. 690.

40. Nottingham County Record Office, BB34.8, 'Gallows Rememberancer for 1763', p. 25.

41. Dorset Record Office, NG/PRl, Prison Admission and Discharge Registers, 1782-1901,' Case of John Anderson Constable arrest of Elizabeth, otherwise known as Betty Marsh'; D/SEN/3/7/8, 22 June 1792 confirms a bond between the two main surgeons of Dorchester, John Coombs and Philip Coombs; D/SEN/3/7/10-11, 24-25 February 1794 likewise indicates a conveyance of property where John lived at Sturminster Newton and Philip at Shillingstone after their respective marriages, although they worked from medical premises in Dorchester.

42. Editorial (1814), 'Murders in Cornwall', Journal of The Universal Magazine of Knowledge and Pleasure, Provincial Occurrences, December issue, pp. 517-8, where it was alleged that William Burns may have killed a man in Dublin too; see also, Rita Margaret Barton (1970), Life in Cornwall in the early nineteenth-century: being extracts from the West Briton newspaper in the quarter century from 1810-1835 (Cornwall: D. Bradford Barton Ltd).

43. The National Archives, (hereafter TNA), T90/170, Burns (Cornwall, 1814), ref. 7306891, expenses claimed back by Joseph Edwards, Undersheriff.

44. Rev. Daniel and Mr Samuel Lysons (1814), Magna Britannica Volume 3, Cornwall, (London: Cadell and Davies in the Strand), p. cxiii.

45. TNA, PROB 11/2066/422, Will of Dr Coryndon Rowe, Doctor in Medicine of Dockacre Launceston, Cornwall. His portrait is on display today at Launceston Museum, where his anti-slavery stance is celebrated in the county history. The Sheriff Cravings confirm he dissected bodies in $1793,1796,1812,1815,1821$, \& 1821.

46. See, TNA, Sheriff's Cravings, E389/253/355; E389/253/359, $1814 / 03 / 31$, Burns/Hamley dissection. and is listed as doing dissections for 1820, 1821 and 1828; Lancet, Volume 2 (1836), p. 685, calls him a penal surgeon and coroner who gave evidence on the Medical Witnesses Bill. It debated the cost of an autopsy and who should open the body. Hamley was unusual for being medically not legally qualified to serve as coroner.

47. I am grateful for an advance copy of Owen Davies and Francesca Matteoni (2015), 'A virtue beyond all medicine: The hanged man's hand, gallows tradition and healing in eighteenth and nineteenth-century England', Social History of Medicine, (May, 2015), Issue 2, in draft copy pp. 1-37, point made at p. 30. 
48. Jessica Synder Sachs (2002), Time of Death: The True Story of the Search for Death's Stopwatch (New York: QPD for William Heinemann at the Random House Group Ltd), p. 6.

49. Simon Devereaux (2008), 'Recasting the Theatre of Execution: the Abolition of the Tyburn Ritual', Past and Present, Vol. 202, 127-74.

50. For a complete history of body trafficking after 1832, see, Hurren, Dying for Victorian Medicine. permits use, duplication, adaptation, distribution and reproduction in any medium or format, as long as you give appropriate credit to the original author(s) and the source, provide a link to the Creative Commons license and indicate if changes were made.

The images or other third party material in this book are included in the work's Creative Commons license, unless indicated otherwise in the credit line; if such material is not included in the work's Creative Commons license and the respective action is not permitted by statutory regulation, users will need to obtain permission from the license holder to duplicate, adapt or reproduce the material. 